\title{
Water-Induced Damage in Microporous Carbonate Rock by Low-Pressure Injection Test
}

\author{
Davide Geremia ${ }^{1}$ (D) $\cdot$ Christian David ${ }^{1} \cdot$ Fanny Descamps ${ }^{2} \cdot$ Beatriz Menéndez $^{1} \cdot$ Christophe Barnes $^{1}$. \\ Sara Vandycke ${ }^{2} \cdot$ Jérémie Dautriat $^{3} \cdot$ Lionel Esteban $^{3} \cdot$ Joel Sarout $^{3}$
}

Received: 1 July 2020 / Accepted: 15 February 2021

(c) The Author(s), under exclusive licence to Springer-Verlag GmbH, AT part of Springer Nature 2021

\begin{abstract}
In the present work, we investigate the mechanical weakening and deformation induced by water on a microporous carbonate rock, the Obourg Chalk from Mons Basin (Belgium), through conventional triaxial tests and injection tests. The injection tests were conducted by waterflooding critically loaded rock samples, initially in dry condition, in a way to minimize the variations in the effective pressures. Furthermore, the samples were instrumented with P-wave piezoelectric transducers to provide active ultrasonic monitoring while injecting. The results show a significant reduction in the mechanical strength of this chalk. Analysis of the mechanical tests and the associated deformation allows us to describe the mechanical behavior as a function of the confining pressure, which draws a brittle-ductile transition spanning from low to high confining pressure. The injection tests, moreover, revealed that the amount of water injected before triggering mechanical instability decreases exponentially with respect to the applied differential stress on the rock sample. The data, therefore, suggest that the failure might be controlled by a mechanical coupling between the water-invaded zone and the dry one. Since water-weakening plays an important role in several fields like oil industry, through secondary and tertiary recovery of hydrocarbons, Enhanced Geothermal Systems (EGS), as well as in the mechanical stability of underground cavities, the outcome of this work is of primary importance in mitigating any kind of problems related to these operations.
\end{abstract}

Keywords Water-weakening $\cdot$ Injection tests $\cdot$ Mechanical tests $\cdot$ Carbonate rocks $\cdot$ Chalk

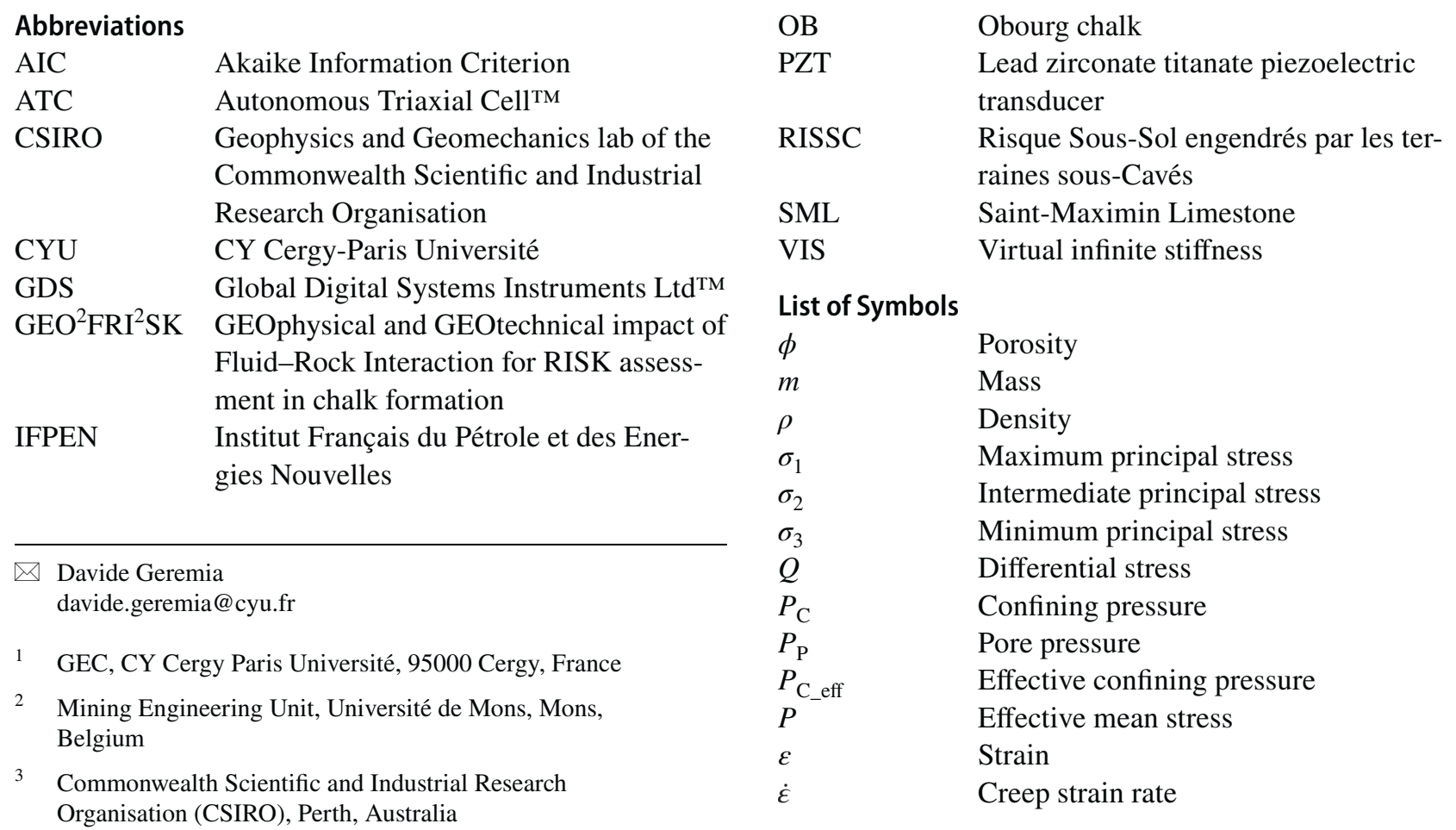




$\begin{array}{ll}L & \text { Sample length } \\ \varepsilon_{\mathrm{v}} & \text { Volumetric strain } \\ \varepsilon_{\mathrm{a}} & \text { Axial strain } \\ \varepsilon_{\mathrm{r}} & \text { Radial strain } \\ V_{\mathrm{P}} & \text { P-wave velocity } \\ K & \text { Bulk modulus } \\ \alpha & \text { Biot's coefficient } \\ \sigma^{*} & \text { Normalized stress } \\ \sigma_{\mathrm{C}} & \text { Differential stress for injection test } \\ \sigma_{\mathrm{P}} & \text { Triaxial compressive strength } \\ \sigma_{\mathrm{F}} & \text { Frictional strength } \\ \gamma & \text { Surface energy } \\ \gamma^{\prime} & \text { Surface energy in water-saturated } \\ & \text { condition }\end{array}$

\section{Introduction}

It is nowadays well documented that the mechanical properties of rocks can be altered depending on the nature of the saturating fluid without any modification of the effective pressure, thus discarding pore pressure effects which can produce hydrofracturing. In fact, the presence of aqueous fluids itself may induce chemical and/or physical alterations, which lead to a mechanical strength reduction, commonly referred to in the literature as water-weakening.

Specific physical mechanisms were proposed by different authors to account for the water-weakening. Among them, the capillary suction mechanism assumes that the rock contains some water even in a dry state, thus increasing the cohesion between the grains by a capillary force (Delage et al. 1996; Schroeder and Shao 1996). This strengthening is lost when such structures are flooded by water. Other mechanisms appeal for chemical effects like the intergranular enhanced pressure solution, where the interplay between the dissolved calcite and chemical species in the open pore space promotes a stronger dissolution near the grain-grain contacts (Heggheim et al. 2005). A combination of physicochemical processes has also been observed to play a major role: Risnes et al. (2005) for instance associated the weakening to an additional pressure due to the adsorbed water layer onto the grain surfaces which is added to the pore fluid pressure, thus decreasing further the effective pressure at the grain contacts. Røyne et al. (2011), by contrast, demonstrated through double torsion experiments on calcite, that the surface energy $\gamma$, which is defined as half of the work necessary to cut a solid body into two new surfaces, decreases with the water content from $0.32 \mathrm{~J} / \mathrm{m}^{2}$ (dry calcite surface) to $0.15 \mathrm{~J} / \mathrm{m}^{2}$ (wet calcite surface). Røyne et al. (2015), moreover, claim, based on atomic force microscopy observations, that a hydration layer on the grain surfaces at the grain to grain contact produces a repulsive force that accounts for a weakening which is consistent with the decrease of about $50 \%$ in surface energy, observed on calcite (Røyne et al. 2011).

In scenarios like the secondary recovery of hydrocarbons or in enhanced geothermal systems (EGS), attention has been mostly paid on issues linked to the reservoir stimulation to increase transmissivity. A poor investigation has been addressed to the fluid-rock interaction that plays a key role when dealing with the injection of a fluid not in equilibrium with the reservoir. So far, most experimental works on injection tests were focused on the development of fracturing with increasing the pore pressure (e.g. Stanchits et al. 2011) or injecting different aqueous solutions into a previously saturated rock specimen with deionized water (e.g. Madland et al. 2011). Few authors concentrated on highlighting the deformation processes during the water saturation, with no variation in the effective stresses. Homand and Shao (2000) adopted a similar procedure to study the strain induced by water injection on mechanically loaded Liège chalk sample, however, without triggering failure. In David et al. (2015b), for instance, in the framework of a research project involving researchers from CY Cergy Paris Universite (Cergy-Pontoise, France) and CSIRO (Perth, Australia), they conducted injection experiments on critically triaxially loaded Sherwood sandstone samples (David et al. 2015b; Dautriat et al. 2016). They showed how replacing the pore fluids (air or oil) by water with a very low injection pressure, caused the rock to fail catastrophically, with the production of a complex deformation located mostly in the water-invaded zone. It seems, therefore, that water causes the rock to undergo a loss of cohesion (David et al. 2015b), which results from intense damaging processes. Based on these experiments performed on sandstones, we conducted two series of experiments at CYU and in CSIRO whose aim was to extend the experimental methodology to carbonate rocks to investigate the strength reduction and deformation associated with the water-weakening. Moreover, among the carbonates, chalk is known to host huge amount of hydrocarbons (e.g. North Sea), therefore, his economic importance is one of the most relevant aspect.

\section{Material}

In this study, we investigate the behavior of Obourg Chalk. This rock comes from the Mons Basin. Connected to the Paris Basin (Fig. 1), the Mons Basin is traditionally defined by the extension area of Meso-Cenozoic sediments that accumulated within an East-West elongate subsiding zone in southwestern Belgium. This 300 m-thick pile of sediments settled in a small but actively subsiding area (Dupuis and Vandycke 1989). Sedimentation initiated in the Lower Cretaceous with continental siliciclastics and continued under marine conditions during the Cretaceous, resulting in chalk 


\section{For personal use}

Water-Induced Damage in Microporous Carbonate Rock by Low-Pressure Injection Test

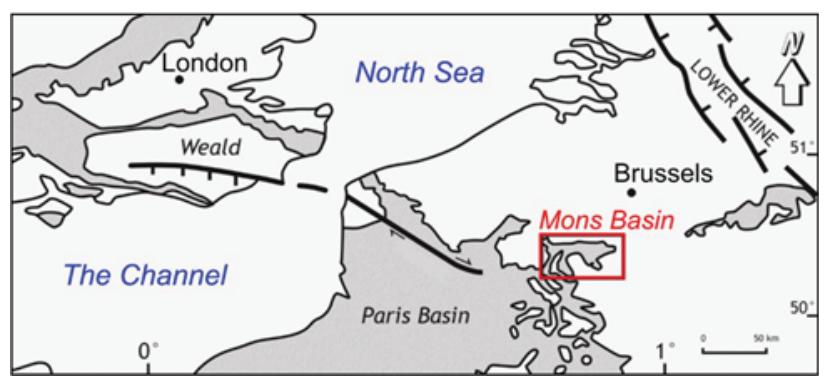

Fig. 1 Location of the Mons Basin in the Chalk district (grey) in NW Europe

formation. More changing environments occurred during the Tertiary era.

The structural context is part of NW Europe geodynamics. Particularly, in the Mons Basin, extensional tectonics initiated at least during the Lower Cretaceous and lasted until the Maastrichtian (Vandycke et al. 1991; Vandycke 2002). In terms of brittle tectonics, white chalk is able to record geodynamic events of the European platform during and after the Cretaceous.

Obourg Chalk is a fine-grained white chalk (Robaszynski et al. 2002) that formed during the Campanian. The maximum burial paleodepth is estimated to $200-250 \mathrm{~m}$ (Dupuis and Vandycke 1989). The samples were collected in a quarry located in Harmignies (Mons, Belgium). In the literature, it is also sometimes referred as Mons Chalk (Voake et al. 2019). It is composed of almost $100 \%$ calcite (less than 1\% insoluble residue; (Faÿ-Gomord et al. 2016) and is considered as a good analogous for reservoir chalk in the North Sea (Fabricius 2007). The main petrophysical properties are given in Table 1 . The porosity is high (43\% on average) whereas the permeability is low $\left(6.4 \times 10^{-16} \mathrm{~m}^{2}\right.$ on average), which is typical of chalk. Pore radii are also typical of this kind of chalk.

$\mathrm{P}$ and $\mathrm{S}$ wave velocities were determined for dry samples. P-wave velocity varies between 2200 and $2700 \mathrm{~m} / \mathrm{s}$, depending on the sample porosity. S-wave velocity ranges between 1400 and $1500 \mathrm{~m} / \mathrm{s}$.

Faÿ-Gomord et al. (2016) describe Obourg Chalk as a micritic chalk. It has a mudstone dominated texture. The main components are very well preserved elliptic coccoliths fragments (Fig. 2a), typically in the range of 2 to $8 \mu \mathrm{m}$ diameter and $0.5 \mu \mathrm{m}$ thickness (Faÿ-Gomord et al. 2017). They form a microrhombic matrix texture with rare authigenic calcite crystals (Faÿ-Gomord et al. 2017). From thin section analysis, $1-6 \%$ of grains, mostly planktonic foraminifera, are
Table 1 Petrophysical parameters of Obourg Chalk

\begin{tabular}{ll}
\hline & Obourg Chalk \\
\hline Composition & $99.6-99.9 \% \mathrm{CaCO}_{3}+$ Smectite-Illite, \\
& Clinoptilolite and Apatite (Voake et al. \\
& $2019)$ \\
Grain density & $2720 \mathrm{~kg} / \mathrm{m}^{3}$ \\
Bulk density & $1550 \mathrm{~kg} / \mathrm{m}^{3} \pm 34$ \\
Average porosity & $0.43 \pm 0.013$ \\
Water permeability (triaxial vessel) & $6.4 \times 10^{-16} \mathrm{~m}^{2} \pm 5.9 \times 10^{-16}(0.65 \mathrm{mD} \pm 0.59)$ \\
Gas permeability (permeameter) & $5 \times 10^{-15} \mathrm{~m}^{2} \pm 4.6 \times 10^{-16}(5.1 \mathrm{mD} \pm 0.47)$ \\
Peak pore throat radius (mercury injection) & $0.291 \mu \mathrm{m}$ \\
Peak grain radius (statistical analysis) & $0.74 \mu \mathrm{m}$ \\
\hline
\end{tabular}
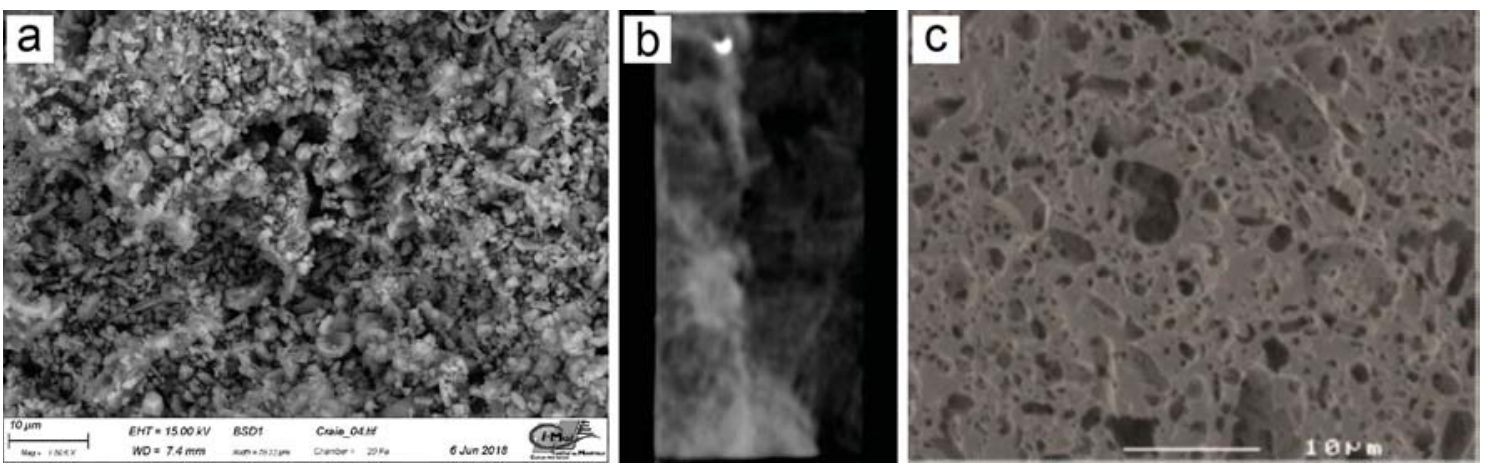

Fig. 2 a SEM picture of an intact Obourg chalk sample; b CT scan on an intact Obourg chalk sample $(80 \times 40 \mathrm{~mm})$; $\mathbf{c}$ SEM picture of porecast, dark areas correspond to dissolved calcite (Faÿ-Gomord et al. 2016) 
observed in the mudstone fabric. This is typical of a deep offshore depositional environment. CT scan image of intact sample in Fig. 2b indicates a very homogeneous matrix texture with sub-vertical inhomogeneities.

The contacts between the fragments are mainly punctic and interparticle porosity is well preserved in the samples. Resin porecasts were used by Faÿ-Gomord et al. (2016) to investigate the shape and distribution of the pore network, by dissolving $30 \mu \mathrm{m}$ thick thin sections impregnated with epoxy-resin in a $10 \mathrm{M}$ hydrochloric acid solution. It revealed a well-connected network of pores displayed as light areas (Fig. 2c). The general fabric is very loose, and cementation is limited to some calcite-cement overgrowths on coccolith fragments.

\section{Experimental Methods}

\subsection{Sample Preparation}

The chalk blocks collected in the quarry were cored perpendicularly to the bedding to produce cylinders of $40 \mathrm{~mm}$ in diameter, they have been then cut and machined to get a length of $80 \mathrm{~mm}$. Prior to any kind of test, the samples have been dried in the oven at a temperature of $60^{\circ}$ for at least $48 \mathrm{~h}$. A petrophysical screening of P-wave velocity, S-wave velocity and porosity has been subsequently conducted with the aim of selecting a uniform group of samples and removing the outliers. For each sample, porosity $\phi$ has been measured using the dry, saturated and immersed mass (respectively, $m_{\mathrm{dry}}, m_{\mathrm{sat}}$ and $m_{\mathrm{imm}}$ ) applying the following formula:

$\phi=\left(\frac{m_{\mathrm{sat}}-m_{\mathrm{dry}}}{m_{\mathrm{sat}}-m_{\mathrm{imm}}}\right)$

for samples which were not saturated, porosity has been computed using the grain and bulk density ( $\rho_{\text {grain }}$ and $\rho_{\text {bulk }}$, respectively):

$\phi=1-\left(\frac{\rho_{\text {bulk }}}{\rho_{\text {grain }}}\right)$

with $\rho_{\text {grain }}$ representing the density for pure calcite $(2720 \mathrm{~kg} /$ $\mathrm{m}^{3}$ ), confirmed by helium pycnometer on chalk grains. For the experiments in water-saturated condition, the rock samples have been saturated with tap water by first vacuuming them inside a bell jar for at least $6 \mathrm{~h}$ and then introducing de-aired water. Samples are left in the jar for at least $48 \mathrm{~h}$.

\subsection{Methods for Mechanical Experiments}

To understand the water-weakening nature of the studied chalk, mechanical tests have been conducted in the
Geomechanics lab at CYU and in the Geophysics and Geomechanics lab at CSIRO in Perth.

In the following, the compressive principal stresses $\sigma_{1}$, $\sigma_{2}$ and $\sigma_{3}$ are considered positive. The maximum stress is denoted by $\sigma_{1}$ and the minimum by $\sigma_{3}$, with $\sigma_{1}-\sigma_{3}$ representing the differential stress $Q$. The confining pressure $\left(\sigma_{2}=\sigma_{3}\right)$ is called $P_{\mathrm{C}}$ and the pore pressure $P_{\mathrm{P}}$. The difference between them:

$P_{\mathrm{C}_{-} \text {eff }}=P_{\mathrm{C}}-P_{\mathrm{P}}$

is the effective confining pressure and:

$P=\frac{\left(\sigma_{1}+2 \sigma_{3}\right)}{3}-P_{\mathrm{P}}$

is the effective mean stress. Consistently with the sign convention for stresses, positive strains represent shortening or volume reduction. We computed the strain $\varepsilon$ by $\left(L_{t}-L_{0}\right) / L_{0}$ and the strain rate (or creep rate) $\dot{\varepsilon}$ dividing a strain interval by the time interval; with $L_{t}$, the sample length at the defined time $t$ and $L_{0}$ the initial sample length. In this work, the experiments conducted in water-saturated conditions are also called "wet" tests.

The experimental rig used at CYU is shown schematically in Fig. 3. It is composed of a Sanchez Technologies $^{\mathrm{TM}}$ triaxial pressure cell with maximum confining pressure $30 \mathrm{MPa}$, mounted on a VIS loading frame from GDS Instruments $\mathrm{Ltd}^{\mathrm{TM}}$. with maximum axial load $100 \mathrm{kN}$ and servo-controlled axial displacement and load. Axial force is measured by a load cell located outside the pressure vessel with an accuracy of $0.1 \%$; the axial displacement is derived from the rotation of the stepping motor controlling the axial motion (accuracy $1 \mu \mathrm{m}$ ). Two GDS pressure-volume controllers allow one to apply confining and pore pressures with a precision of $\pm 10 \mathrm{kPa}$. The hydrostatic pressure on the rock sample is obtained by applying equal axial stress and confining pressure. The pore and confining pressures are measured in two ways: with internal transducers, located inside the GDS controllers and, through three external high precision Keller ${ }^{\mathrm{TM}}$ pressure transducers (confining, top and bottom pore pressures) located closer to the sample. Volume resolution of the GDS controllers is $\pm 1 \mathrm{~mm}^{3}$. For the test in water-saturated conditions, the volumetric strain is derived from the volume variation of the pore pressure GDS controller. In dry conditions, when a hydrostatic stress is applied, we assumed the axial strain to be equal to the radial strain so that the volumetric strain is given by:

$\varepsilon_{v}=3 \times \varepsilon_{\text {axial }}$

which, however, it has not been involved in any further computation.

The rock sample is placed inside a neoprene sleeve (Fig. 4) to be isolated from the confining fluid. A 


\section{For personal use}

Water-Induced Damage in Microporous Carbonate Rock by Low-Pressure Injection Test

Fig. 3 Experimental rig at CY

University (Modified after Wild et al. 2015)
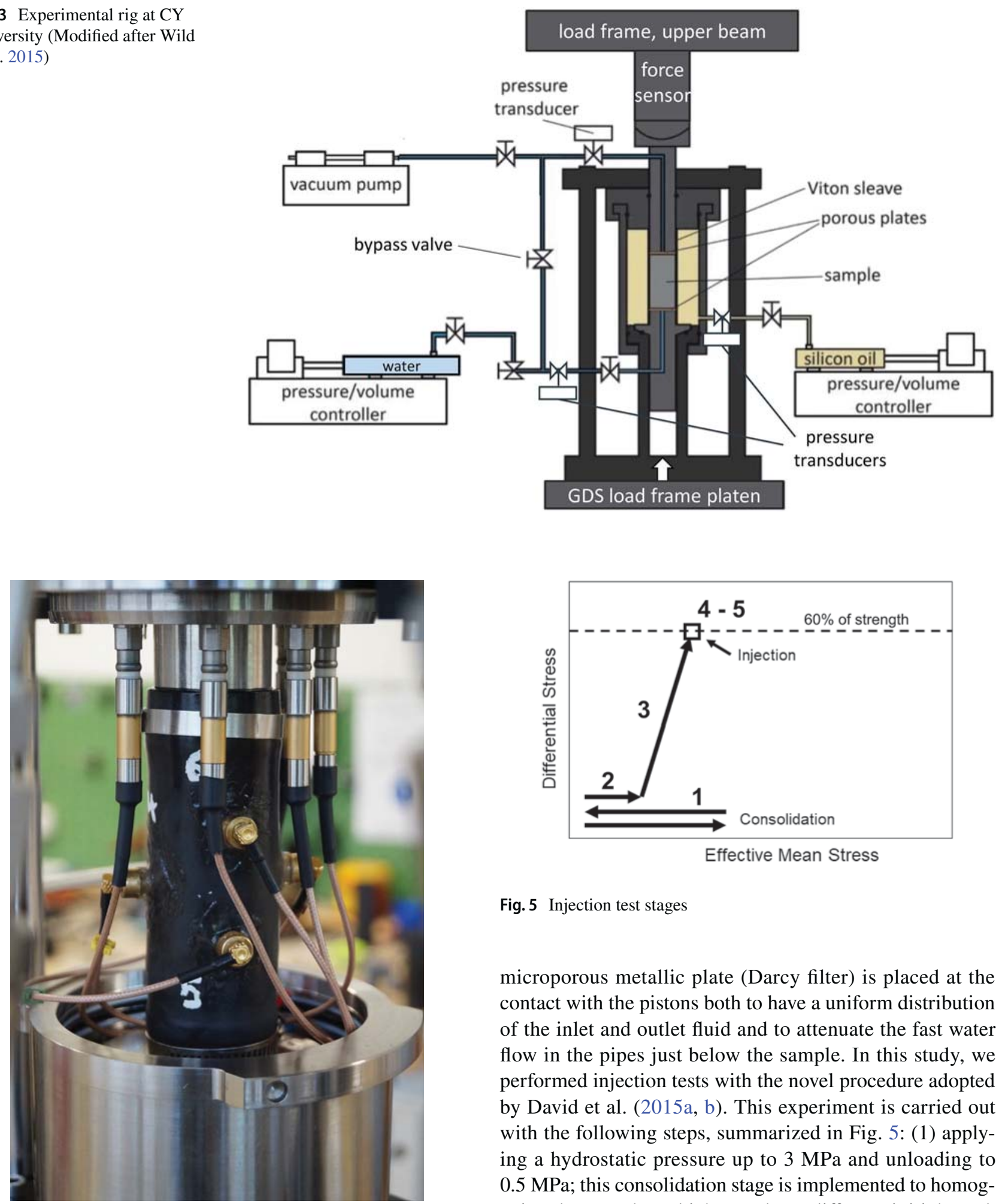

Effective Mean Stress

Fig. 5 Injection test stages

microporous metallic plate (Darcy filter) is placed at the contact with the pistons both to have a uniform distribution of the inlet and outlet fluid and to attenuate the fast water flow in the pipes just below the sample. In this study, we performed injection tests with the novel procedure adopted by David et al. (2015a, b). This experiment is carried out with the following steps, summarized in Fig. 5: (1) applying a hydrostatic pressure up to $3 \mathrm{MPa}$ and unloading to $0.5 \mathrm{MPa}$; this consolidation stage is implemented to homogenize the samples which may have different initial crack content and thus increasing reproducibility (David et al. 2015b); (2) applying the target confining pressure with a rate of $0.125 \mathrm{MPa} / \mathrm{min}$; (3) increasing the axial stress with a constant stress rate between 0.15 and $0.20 \mathrm{MPa} / \mathrm{min}$ and up to a previously defined target (e.g. $60 \%$ of estimated strength in Fig. 5); (4) stabilization for 30-60 min to stabilize the
Fig. 4 Rock sample jacketed with a neoprene sleeve with PZT transducers in place 
strain rate and (5) injection of water from the bottom of the sample. During the injection stage, the pressure difference between the fluid inlet and outlet is $0.2 \mathrm{MPa}$ and is due to an applied fluid pressure at the lower end of the sample of $\sim 0.12 \mathrm{MPa}$ and, at the same time, to a vacuuming from the upper part (to avoid air trapping during the injection), leading to a negative pressure of $\sim 0.08 \mathrm{MPa}$. We performed two series of injection tests at two different confining pressures (1.5 MPa and $4 \mathrm{MPa}$ ).

To plan an injection test, it is necessary to have a good knowledge of the rock strength to avoid the applied axial stress to be too close or even to exceed the failure stress. For this purpose, we first conducted two series of experiments in dry and water-saturated conditions to build the failure envelope. To pursue that, we performed hydrostatic and triaxial tests. Four hydrostatic tests (two in dry and two in water-saturated conditions) have been done by increasing hydrostatically the stress at a constant rate of $0.1 \mathrm{MPa} / \mathrm{min}$ beyond the critical pressure $P^{*}$ at the onset of pore collapse and grain crushing. Thirteen conventional triaxial tests have been carried out on both dry and water-saturated samples at different confining pressures and following the same procedure as the injection tests, except that the axial load is increased at a constant strain rate of $1 \times 10^{-6} \mathrm{~s}^{-1}$ up to failure and beyond. For the wet experiments, the pore fluid pressure was kept constant at a value of $1 \mathrm{MPa}$ (except for a test done at $0.5 \mathrm{MPa}$ of effective confining pressure, where the fluid pressure was $0.5 \mathrm{MPa}$ ).

As shown in Fig. 4, six P-wave piezoelectric transducers (PZTs) with $5 \mathrm{~mm}$ of diameter $(0.5 \mathrm{MHz}$ resonant frequency) are installed directly in contact with the sample through the sleeve, for active and passive acoustic monitoring. The PZTs are placed in brass holders with a surface shaped so that it can perfectly match the curved rock surface. Six holes are made in the sleeve to have three pairs of transducers facing each other as shown in Fig. 6. They are distributed on three horizontal planes, with the lower and the upper ones with transducers in the same $\mathrm{N}-\mathrm{S}$ oriented vertical plane and the middle one with transducers aligned in an E-W oriented vertical plane. With this configuration, we have been able to measure P-wave velocity $\left(V_{\mathrm{P}}\right)$ in 15 different pathways: three horizontal, two vertical, two oblique crossing the cylinder axis (e.g. sensors 5-1) and eight oblique off axis involving the midpoint transducers (e.g. sensors 5-3). For the purpose of this study, only the horizontal (i.e. radial) velocities along the top, bottom and midpoint will be shown. In certain experiments we glued the transducers onto the rock surface; for others, we only placed them in contact with the sample's surface, improving, however, the coupling by applying a little amount of a gel that enhances the acoustic transmission. Finally, a resin is applied around the sensors both to keep them fixed onto the surface and to avoid any leaks of oil from the confining fluid. The acoustic

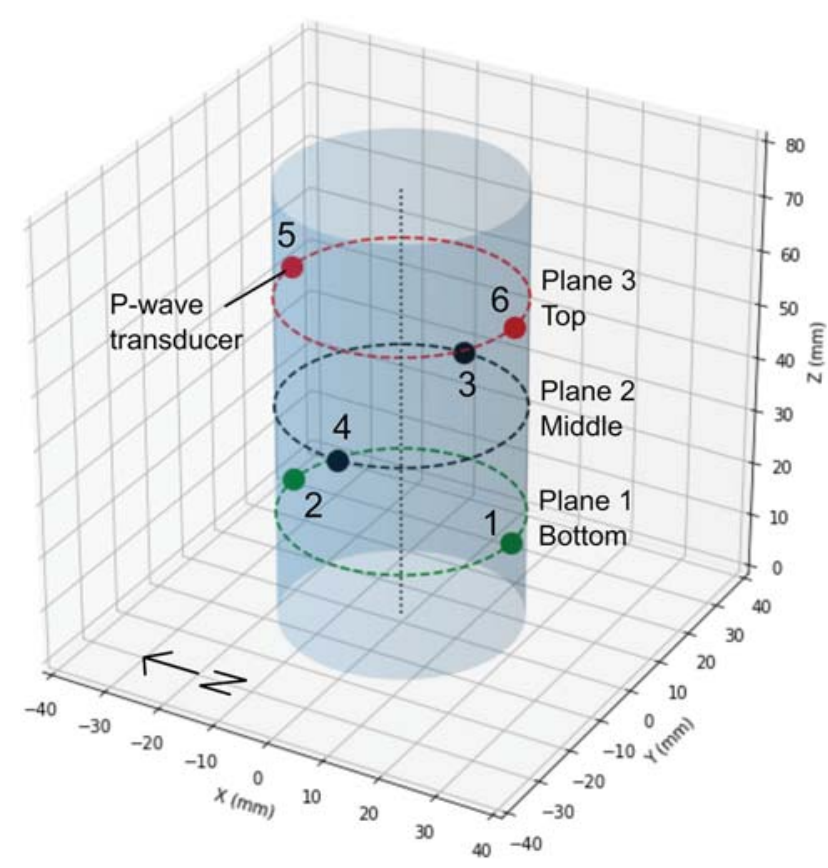

Fig. 6 Location of the six piezoelectric transducers

monitoring is controlled by an AMSYS-5 Vallen Systeme $\mathrm{GmbH}$ (Germany), with six recording channels connected to the sensors, allowing one to operate in two modes: active (wave speed measurement) and passive (acoustic emission AE recording). In the active mode, a proper batch file is used to perform an automatic survey that proceeds this way: every channel is switched between pulser and receiver so that each time one channel is pulsing four times while the other five channels are recording, resulting in 24 waveforms registered, including the emitted pulses. This is then reproduced throughout the different channels so that, at the end of each survey, 144 ( $24 \times 6$ channels) waveforms are recorded, including the emitted pulses. The time interval between the surveys varies from 45 to $60 \mathrm{~s}$.

The registered signals are then exported from the software and, through a proper script file, the P-wave first arrivals are picked automatically using the Akaike Information Criterion (AIC) (Leonard and Kennett 1999). Another script file is adopted to convert the travel times into P-wave velocity using the correct distances between the different pairs of sensors. No strain-dependent change in the travel path length has been considered since we checked for the tested rock that the impact on velocity was negligible (variation of $25 \mathrm{~m} / \mathrm{s}$ at maximum applied stress).

Different sources of error have been considered for estimating the uncertainty in velocity measurements: (1) error in picking the P-wave first arrival; (2) error in measuring the correct distances between the transducers; (3) error in deriving the correction factor due to the coupling between the sensors and the sample and (4) averaging of the P-wave 


\section{For personal use}

Water-Induced Damage in Microporous Carbonate Rock by Low-Pressure Injection Test

velocities computed from the 4 pulsing done by every channel in each survey.

No data about the passive mode will be taken into consideration in this work since we recorded only few acoustic emissions during each mechanical test. Several reasons may explain this behavior: the tested rock might have strong energy attenuation; the energy itself could be very low or even, the prevalence of plastic deformation with respect to the brittle one, which provides less wave energy.

\subsection{Mechanical Experiments at CSIRO}

Six mechanical tests, including triaxial and injection tests, were performed in the Geomechanics lab in CSIRO during a short stay (2 months) in Australia.

The rock blocks were cored, and the cores machined to obtain cylinders of about $38 \mathrm{~mm}$ in diameter and $78 \mathrm{~mm}$ in length. As a standard procedure, a medical CT-scan was performed on all the rock specimens, pre- and post-experiments. Then, permeability and porosity were measured using an AP-608 Automated Permeameter Porosimeter (Coretest systems Inc ${ }^{\mathrm{TM}}$ ). This procedure is also used as a screening to select the most homogeneous and similar samples, avoiding fractures and features that could disturb the experiments. Series of triaxial and injection experiments, at 1.5 $\mathrm{MPa}$ confining pressure, were conducted on two different group of chalk samples, with slightly different porosity. The first group $\left(\mathrm{CS} \_\mathrm{H}\right)$ has a mean porosity of $43.3 \%( \pm 0.12 \%)$ and the second one (CS_L) has an average porosity of $42.7 \%$ $( \pm 0.14 \%)$.

The mechanical tests were performed with an Autonomous Triaxial Cell (ATC ${ }^{\mathrm{TM}}$ ); for a complete description, see Sarout et al. $(2014,2017)$ and Delle Piane and Sarout (2016). This experimental setup, which differs from the one used at CYU, is composed by three actuator pumps which control the axial force, confining pressure and pore pressure. The cell is built so that the confining pressure is applied hydrostatically by a single pump. The axial displacement is measured through two LVDTs placed on the sides of the rock sample. Furthermore, a flexible cantilever was installed on the middle part of the specimen to measure the radial displacement. From the latter, the volumetric strain was computed using the following equation:

$\varepsilon_{v}=\varepsilon_{\text {axial }}+\left(2 \times \varepsilon_{\text {radial }}\right)$

Sixteen PZTs (0.5 MHz resonant frequency) were placed onto the specimen surface through the sleeve, allowing one to measure the P-wave velocity in a similar configuration displayed in Dautriat et al. (2016), with the addition of two PZTs in the upper and lower piston, resulting in many different wave paths in axial, radial and oblique directions.
However, this comprehensive set of acquired data is still being processed and will not be discussed in this work.

\subsection{Imbibition Test}

An imbibition test was also conducted to characterize water migration driven by capillary forces through the rock sample and how it influences the P-wave propagation. The setup is the same as the one used by David et al. (2015b). The rock sample is hooked under an electronic balance to register the mass variation during imbibition. A small water reservoir is permanently in contact with the bottom of the sample which is instrumented with six PZTs in the same configuration as in the mechanical tests, allowing an active ultrasonic monitoring. The raising water will influence the different wave paths between the P-wave transducers, successively from bottom to top. This simple experiment was used to study the relationship between the waterfront position and the variation in the P-wave velocity: it is shown that the latter is a good proxy to invert the extension of the water-invaded zone inside the pressure vessel in the mechanical tests.

\section{Results}

In the following, the results obtained from triaxial, hydrostatic and injection tests are displayed, as well as the outcome of ultrasonic monitoring on selected experiments only. The denomination of the samples for the triaxial tests is structured as follow: the first two letters of the formation name (Obourg) which is followed by the confining pressure expressed in bar and a letter indicating the fluid condition (D or $\mathrm{W}$ for dry and wet, respectively). For the injection tests, the confining pressure is followed by the applied differential stress (in bar). For instance, for an injection test carried out at $P_{\mathrm{C}}=1.5 \mathrm{MPa}$ and differential stress $=7 \mathrm{MPa}$ the designation is OB15-70, whereas, for a triaxial test conducted in dry condition at the same confining pressure as before, it will be OB15-D.

\subsection{Results for Triaxial and Hydrostatic Tests}

Figure $7 \mathrm{a}, \mathrm{b}$ shows the two sets of triaxial tests in dry and water-saturated conditions, conducted at effective confining pressures between 0.5 and $11 \mathrm{MPa}$. Note that the $y$-axis scale is the same on both figures. There is a clear difference in the mechanical behavior between dry and wet conditions with a much lower mechanical strength for the wet rock samples. As already reported in previous studies, our results show that water produces a significant weakening in carbonate rocks (Heggheim et al. 2005; Risnes et al. 2005; Baud et al. 2009; Voake et al. 2019; Homand and Shao 2000). This behavior has also 
Fig. 7 Mechanical data for triaxial compression tests and injection tests: a Triaxial experiments at different confining pressures on dry Obourg chalk samples, performed at CYU. The confining pressure is indicated by numbers next to each curve; $\mathbf{b}$ Triaxial experiments at different effective confining pressures on wet Obourg chalk samples, performed at CYU; c. Triaxial experiments at $P_{\mathrm{C}}=1.5 \mathrm{MPa}$ on dry and wet Obourg chalk samples, performed at CSIRO. Two injection tests conducted at $P_{\mathrm{C}}=1.5 \mathrm{MPa}$ and $Q=7.1 \mathrm{MPa}$ (OB15-71) and 7.4 MPa (OB1574) are compared in the graph with the triaxial tests

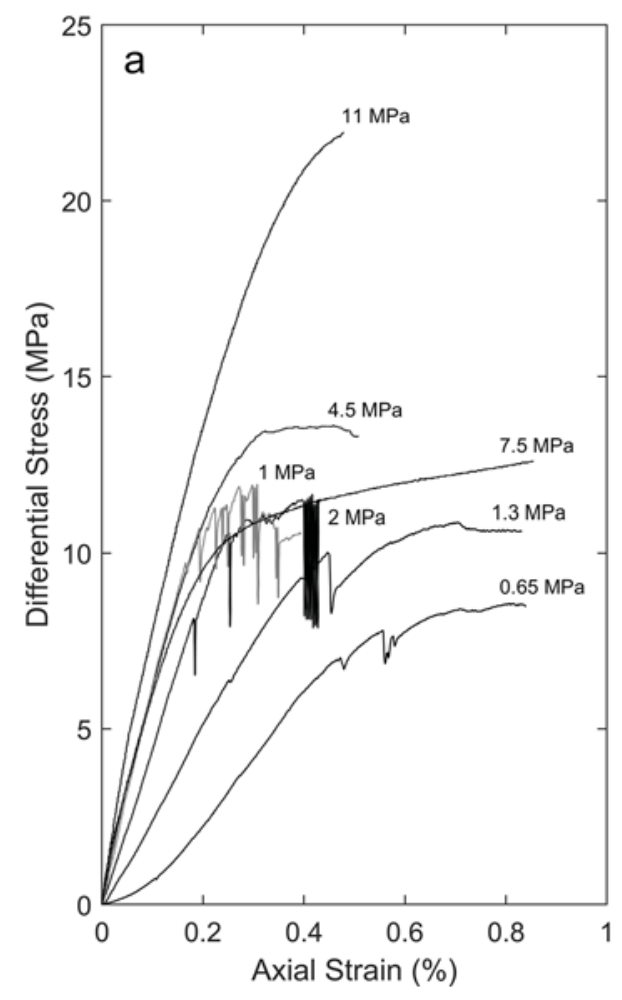

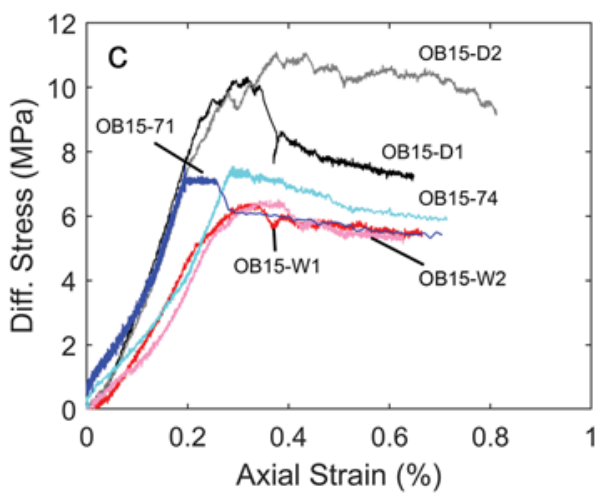

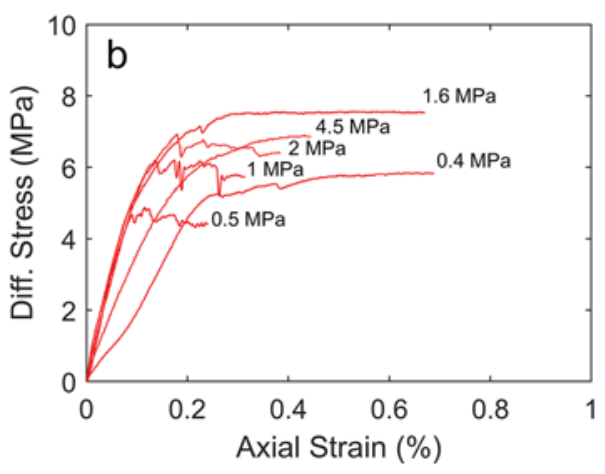

been observed in sandstones (Wong and Baud 2012; David et al. 2015b; Dautriat et al. 2016). Furthermore, the mechanical behavior outlines a difference depending on $P_{\mathrm{c}_{-} \text {eff. }}$. Below $P_{\mathrm{c}_{-} \text {eff }},=2 \mathrm{MPa}$, beyond the yield point, the stress-strain curve shows a stabilization with no strain hardening, referred in the literature as an elastic-perfectly plastic behavior (Jaeger et al. 2007). In addition, several stress drops are occurring sometimes, like in the dry test at $P_{\mathrm{c}}=2 \mathrm{MPa}$, which shows a cyclic stress variation with 3.5 MPa in amplitude. Moreover, the onset of these events appears to be more developed under dry condition. Above $P_{\text {c_eff }}=2 \mathrm{MPa}$, the mechanical behavior still displays a stabilization, but the stress drops disappear. Only the test conducted at $P_{\mathrm{c}}=11 \mathrm{MPa}$ in dry condition manifests a continuous stable strain hardening. Nevertheless, in particular cases the mechanical strength depicts a variability which does not correlate with the confining pressure. For instance, among the tests conducted in dry condition at $P_{\mathrm{c}}=1,1.3$ and $2 \mathrm{MPa}$ the higher strength is for the test at lower confining pressure. This is probably due to the heterogeneity of the material. Indeed, our undeformed chalk samples exhibit sub-vertical deformation bands (Fig. 2b). This might generate the scatter observed in the mechanical data.

In Fig. 7c are displayed the triaxial tests (wet and dry) conducted at CSIRO on the two groups CS_L and CS_H at $P_{\mathrm{C}_{-} \text {eff }}=1.5 \mathrm{MPa}$. Many similarities with the CYU tests are found: (1) the peak stresses in dry conditions are higher than in wet conditions and the values are very close to the ones shown in Fig. 7a, b; (2) the mechanical behavior in dry conditions exhibits several stress drops not observed under wet conditions. Unexpectedly, the dry test of the CS_H group (sample OB15-D1, Fig. 7c) shows a clear peak with a more pronounced strain softening at residual strength of 7.4 MPa.

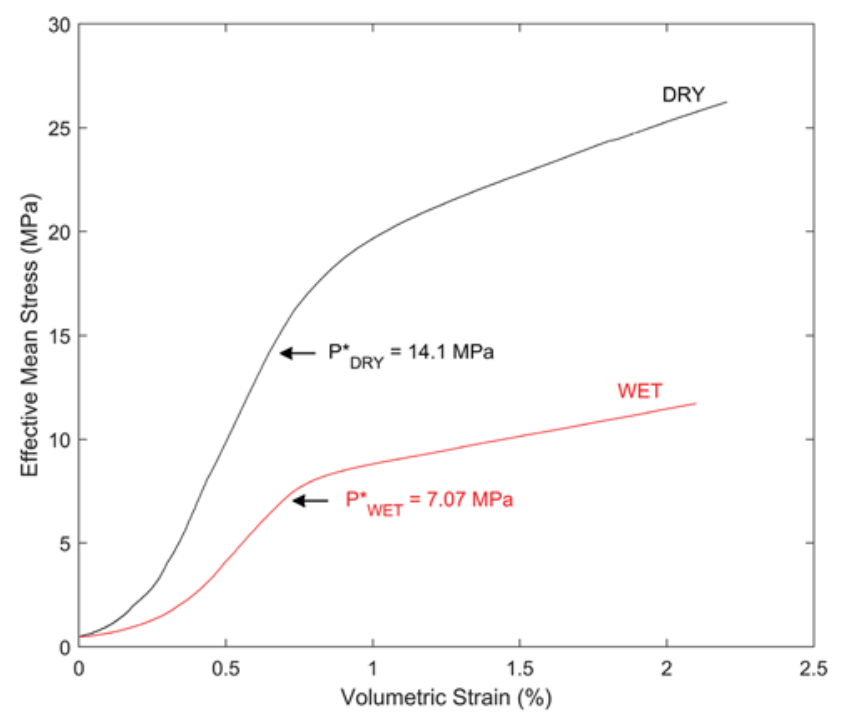

Fig. 8 Effective mean stress versus volumetric strain for representative hydrostatic tests in dry and wet condition on Obourg chalk samples, performed at CYU. The onset of inelastic compaction $P^{*}$ for each saturation condition is shown on the graph 
Figure 8 presents the results of two hydrostatic tests carried out on dry and wet samples. As for the triaxial tests, the yielding stress under hydrostatic loading is lower for the sample in water-saturated condition. The critical pressure at the onset of inelastic compaction is $P^{*}=7.07 \mathrm{MPa}$ in wet and $P^{*}=14.1 \mathrm{MPa}$ in dry condition with a $P^{*}{ }_{\text {wet }}$ to $P^{*}$ dry ratio of 0.5 .

Whereas the weakening is clearly manifested in the mechanical strength, the Young's modulus, derived from the triaxial tests, seems to be just slightly influenced, with values that span from 3.45 to $6.68 \mathrm{GPa}(5.26 \mathrm{GPa}$ on average) in wet condition and from 4.54 to $9.22 \mathrm{GPa}$ (mean value $6.14 \mathrm{GPa}$ ) in dry condition with a large scatter in both cases (Fig. 7). In addition, they display no correlation with confining pressure. In contrast, the bulk modulus $K$, computed from the hydrostatic tests, is reduced by a factor 2 in the wet sample, from 2.98 to $1.56 \mathrm{GPa}$, giving a ratio $K_{\text {wet }} / K_{\text {dry }}$ of 0.52 which is very similar to the ratio obtained for the critical pressures $P^{*}$. Furthermore, they yield a Biot's coefficient $\alpha$ of 0.96 and 0.98 , respectively, in dry and wet conditions, computed by:

$\alpha=1-\frac{K_{\mathrm{b}}}{K_{\mathrm{S}}}$

with $K_{\mathrm{S}}$, the solid modulus (77 GPa for calcite) and $K_{\mathrm{b}}$, the bulk modulus.

The presence of water induces elastic weakening mostly noticeable on the bulk moduli rather than Young's moduli. Risnes et al. (2005) also observed no striking difference in the Young's modulus derived by triaxial tests conducted on samples of Liège chalk in different water saturation conditions.

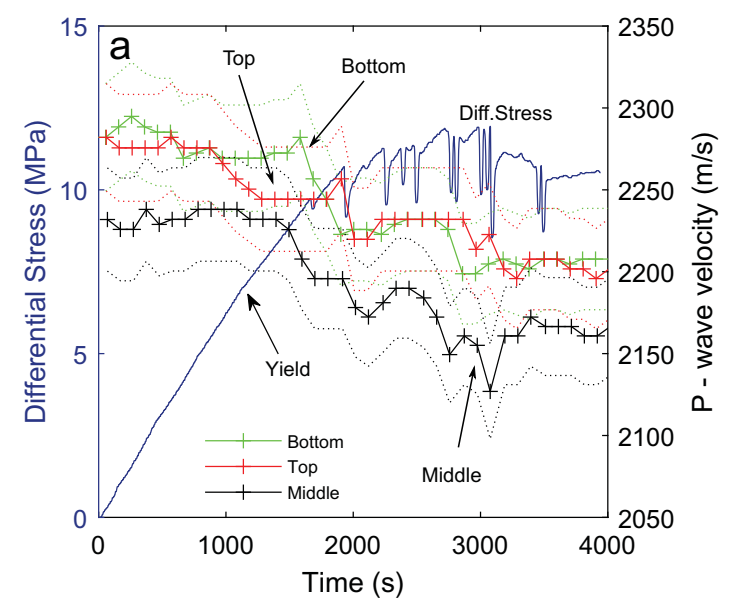

Fig. 9 P-wave velocity variation in function of time for triaxial tests on dry Obourg chalk samples, performed at CYU. In blue is displayed the differential stress versus time. The velocity data are represented
For the triaxial tests, volumetric strains could only be obtained for the tests in wet condition, because they are derived from the volume variation of the pore pressure pump. Dilatancy was observed only in two experiments at $P_{\mathrm{c} \_ \text {eff }}=0.4$ and $0.5 \mathrm{MPa}$. All the tests conducted at $P_{\mathrm{c} \_ \text {eff }}$ higher than $0.5 \mathrm{MPa}$ are accompanied by shear-enhanced compaction promoted by the differential stress. However, in most of the tests, no visual evidence of deformation was found on the rock specimen retrieved from the triaxial cell. A description of thin sections is provided in paragraph 5.1.

Figure $9 \mathrm{a}, \mathrm{b}$ shows the results of the active acoustic monitoring on two triaxial dry tests conducted at $P_{\mathrm{c}}=1$ and 4.5 MPa. In Fig. 9a, the variations of P-wave velocity in three horizontal planes provide a good indicator of the development of damage. In fact, when approaching the yield stress, velocities start to decrease continuously but not homogeneously, as observed also by Nicolas et al. (2016) on Tavel limestone. In Fig. 9a, damage seems to develop from top to bottom, whereas the reverse is true for Fig. 9b. A correlation between the major cyclic stress variation and the velocity drops can also be observed. Similarly, at $P_{\mathrm{c}}=4.5 \mathrm{MPa}$, the P-wave velocity starts decreasing near the yield stress. However, in some cases, it stabilizes with no further variation in the mid and top planes. Further decrease is observed when the mechanical behavior shows signs of strain softening at the end of the test. The onset of P-wave velocity decrease is a proxy for damage development and can be used to define more precisely the yield stresses on our experiments. Nonetheless, the observed velocity differences at the three planes location, highlight the inhomogeneity in the strain field which can be due to a strain localization in fracture and/or deformation bands. Moreover, in the test at higher confining pressure (Fig. $9 \mathrm{~b}$ ) the $V_{\mathrm{P}}$ variation seems to

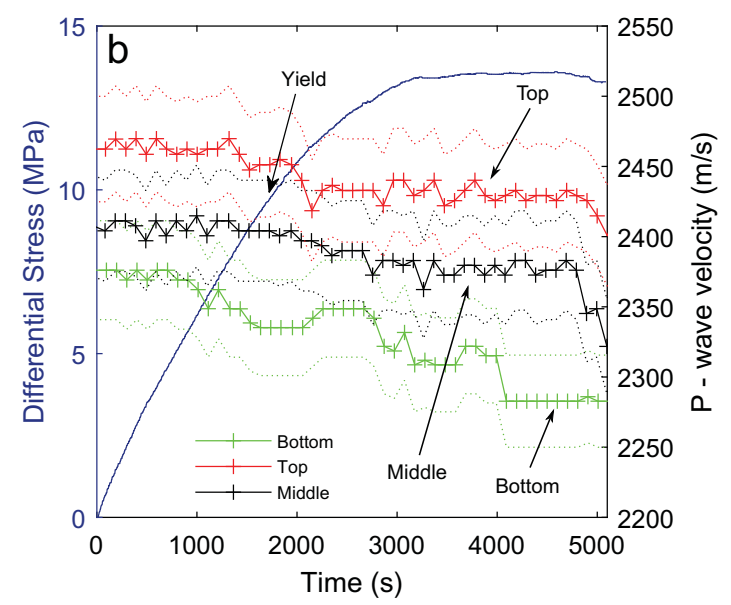

by crosses and the dotted lines depict the error which is on average $\pm 35 \mathrm{~m} / \mathrm{s}$ : a Sample OB10_D $\left(P_{\mathrm{C}}=1 \mathrm{MPa}\right)$; b Sample OB45_D $\left(P_{\mathrm{C}}=4.5 \mathrm{MPa}\right)$ 


\section{For personal use}

D. Geremia et al.

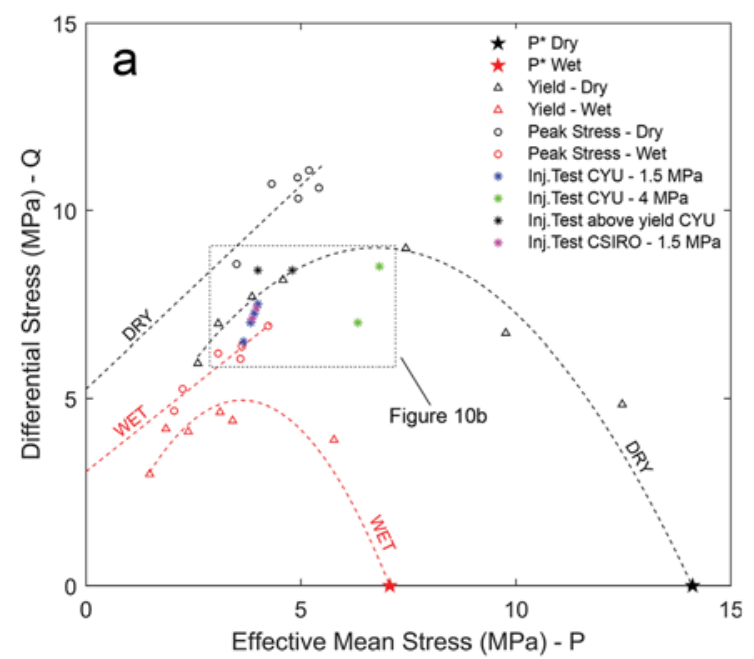

Fig. 10 a Compilation of peak stress, yield stress and $P^{*}$ in the stress space $Q-P$ for triaxial and hydrostatic experiments performed on wet and dry Obourg chalk samples. Stress states for the injection tests are

be more homogeneous in the three levels, indicating a more uniform and diffuse deformation.

In Fig. 10, the critical stress state values in the dry (in black) and wet (in red) tests, corresponding to the peak stress (circles), the yield stress (triangles) and the critical pressure $P^{*}$ (solid stars), are gathered in a $Q-P$ plot with $Q$, the differential stress and $P$, the effective mean stress. As shown in the previous paragraph, the critical stresses are well correlated with $\mathrm{P}$-wave velocity variations, thus, to define them accurately, a combination of criteria involving P-wave velocity and mechanical behavior were used. As expected, the presence of water strongly shrinks the failure and yield envelopes to lower stress values. Moreover, the shape of the two envelopes in wet and dry conditions is comparable with what has been found for several types of limestones (Wong and Baud 2012): Solnhofen (Baud et al. 2000), Tavel (Vajdova et al. 2004), Indiana (Vajdova et al. 2004) and Richemont (Xie et al. 2011) as well as for Liège chalk (Homand and Shao 2000) and Anstrude limestone (Han et al. 2016). The peak stresses are linearly correlated with some scatter for the dry tests, whereas the yield stresses map out an elliptical or parabolic cap. Table 2 gathers the critical results from triaxial and hydrostatic tests.

\subsection{Results for Imbibition Test}

The imbibition test has been properly designed to highlight the P-wave velocity variation relative to the waterfront rise. Figure 11 shows the P-wave velocity variation at the middle pathway of the rock sample versus time. When water is approaching the half of the specimen (position 1 in Fig. 11), velocity starts to be affected resulting in a $V_{\mathrm{P}}$ drop of about $10 \%$. This stage is followed by a stabilization which is

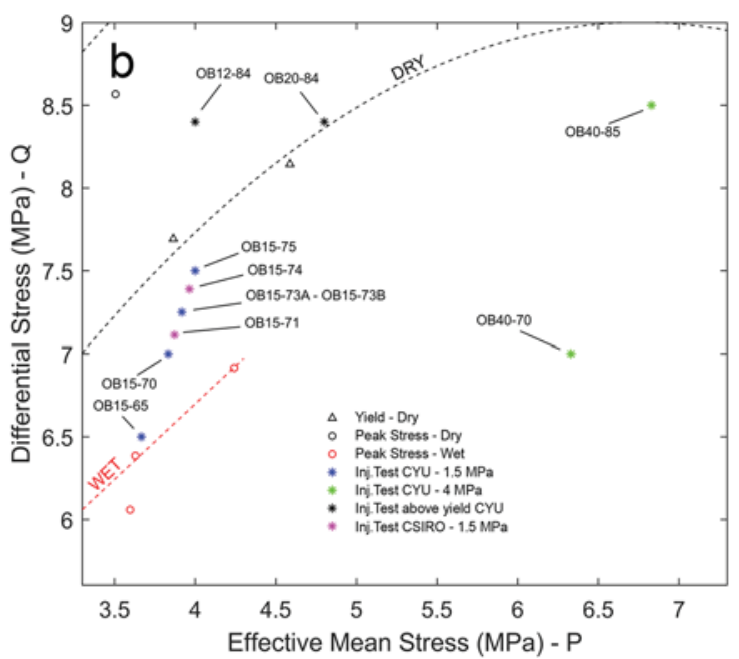

displayed by the asterisks; b Close-up from Fig. 10a displaying the stress state of the injection tests

interrupted by a $V_{\mathrm{P}}$ rise starting when water reaches the top of the sample at position 2 in Fig. 11. The latter observation might be generated by a transition, when the water reaches the top, from a regime dominated by capillary driven fluid motion to diffusion-controlled pore filling. In this way, water tends to completely saturate the pore volume which results in a phenomenon defined in the literature as squirt flow. This mechanism implies that the stress fluctuation generated by the high frequency P-wave passing in the porous medium, generates a pore-pressure gradient which is not quickly equilibrated, resulting in stiffer elastic moduli (Vinciguerra et al. 2006; Mavko et al. 2009). Note that as air remains trapped in the pore space, the complete saturation of the sample is prevented, which impedes the P-wave velocity to increase further.

\subsection{Results for Injection Tests}

With the knowledge of the failure envelope of the Obourg chalk (Fig. 10), the injection tests were planned so that the applied differential stress $Q$ was systematically above the wet (water saturated) failure envelope and below the dry yield envelope, except for two early tests (OB12-84 and OB20-84) conducted in a preliminary calibration stage, where it was higher than the dry yield envelope. Doing so, the experiment proceeds by loading a dry rock sample at a stress state below the yield point to keep the sample in the elastic regime and avoid the development of inelastic deformation induced by the applied load. Figure $10 \mathrm{~b}$ is a close-up of Fig. 10a showing the eleven injection tests performed: seven at $P_{\mathrm{c}}=1.5 \mathrm{MPa}$ (5 at CYU represented by blue asterisks and 2 at CSIRO by purple asterisks), two at $P_{\mathrm{c}}=1.2$ and $2 \mathrm{MPa}$ (both depicted with black asterisks) and two at $P_{\mathrm{c}}=4 \mathrm{MPa}$ 


\section{For personal use}

Water-Induced Damage in Microporous Carbonate Rock by Low-Pressure Injection Test

Table 2 Critical stresses obtained in triaxial and hydrostatic tests under dry and water-saturated conditions. $\mathrm{H}$ in the sample name stands for Hydrostatic test

\begin{tabular}{cllllll}
\hline Sample name & $\begin{array}{l}\text { Confining } \\
\text { pressure } \\
\text { (MPa) }\end{array}$ & $\begin{array}{l}\text { Effective mean } \\
\text { stress at failure } \\
(\mathrm{MPa})\end{array}$ & Peak stress (MPa) & $\begin{array}{l}\text { Yield } \\
\text { stress } \\
(\mathrm{MPa})\end{array}$ & $\begin{array}{l}\text { Critical } \\
\text { pressure } P^{*} \\
(\mathrm{MPa})\end{array}$ & $\begin{array}{l}\text { Pore } \\
\text { pressure } \\
(\mathrm{MPa})\end{array}$ \\
\hline Dry & & & & & & \\
OB07-D & 0.7 & 3.51 & 8.57 & 5.94 & - & - \\
OB10-D & 1.0 & 4.32 & 10.71 & 6.98 & - & - \\
OB13-D & 1.3 & 4.92 & 10.88 & 7.69 & - & - \\
OB15-D1 & 1.5 & 4.94 & 10.32 & - & - & - \\
OB15-D2 & 1.5 & 5.19 & 11.07 & - & - & - \\
OB20-D & 2.0 & 5.42 & 10.60 & 8.14 & - & - \\
OB45-D & 4.5 & 7.44 & - & 8.99 & - & - \\
OB75-D & 7.5 & 9.76 & - & 6.73 & - & - \\
OB110-D & 11.0 & 12.47 & - & 4.84 & - & - \\
OBH-D & - & - & - & - & 14.10 & - \\
Wet & & & & & & 1.0 \\
OB04-W & 1.4 & 2.25 & 5.26 & 4.19 & - & 0.5 \\
OB05-W & 1.0 & 2.05 & 4.67 & 2.98 & - & 1.0 \\
OB10-W & 2.0 & 3.08 & 6.20 & 4.11 & - & 1.0 \\
OB15-W1 & 1.5 & 3.63 & 6.39 & - & - & 1.0 \\
OB15-W2 & 1.5 & 3.65 & 6.45 & - & - & 1.0 \\
OB16-W & 2.6 & 3.60 & 6.06 & 4.63 & - & 0.5 \\
OB20-W & 3.0 & 4.24 & 6.92 & 4.41 & - & - \\
OB45-W & 5.5 & 5.77 & - & 3.89 & - & 7.07 \\
OBH-W & - & - & - & & & \\
\hline & & & & -0 & \\
\hline
\end{tabular}

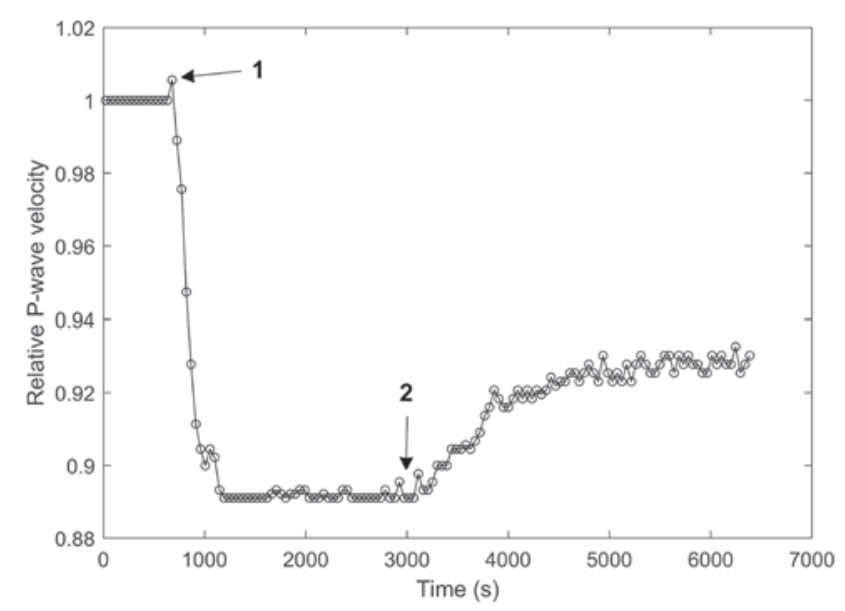

Fig. 11 P-wave velocity variations plotted vs. time during the imbibition test

(green asterisks). Following the stages of pre-consolidation, loading and stabilization depicted in Fig. 5, water injection starts when applying a small pore pressure gradient of about $0.2 \mathrm{MPa}$ between the ends of the sample. A typical example is shown in Fig. 12 with the injection test OB15-70 carried out on a rock specimen loaded at 7.0 MPa differential stress, corresponding to $67 \%$ of the dry peak stress (10.49 MPa). Three parameters are plotted: axial strain, differential stress and volume of injected water normalized to pore volume vs time. Proceeding with the injection, two events ( 1 and 2) characterized by an increase of the axial strain rate correlated to small stress drops can be identified in Fig. 12a, b. It is worth to note that the event 1 is also correlated to a decrease of the water flow rate; in fact, while in the first part it follows a linear trend, it becomes non-linear at the onset of event 1 , with a decreasing slope. Our explanation for this phenomenon is the damaging and loss of porosity of the sample, which decreases the permeability and, therefore, the flow rate; for this reason, we associate this event as the starting point of an enhanced damage. It is worth to remark that even if the applied differential stress is lower than the yield one in dry condition, the sample undergoes creep, with a low strain rate $\left(4.6 \times 10^{-8} \mathrm{~s}^{-1}\right)$ even before injection started. Indeed, we observed on triaxial tests, that even in the linear elastic behavior, this high porous chalk might accumulate some irreversible strain, which is enhanced at the yield.

Increasing further the injection of water, the sample fails after event 2, producing a big stress drop and a sharp increase in strain rate (red arrow in Fig. 12a). A visual inspection of the sample retrieved from the triaxial pressure vessel showed multiple manifestations of failure at the rock surface with different orientations, with a similar inclination of about $30^{\circ}$ with respect to the sample axis (Fig. 12d). 


\section{For personal use}

Fig. 12 Injection tests performed on sample OB15-70. The axial strain (a), differential stress (b) and the normalized volume injected (c) are plotted vs. time starting from the injection stage. The arrows represent critical moments described in the text; $\mathbf{d}$ post-test picture of sample OB15-70. The dashed line highlights some of the damage features produced during injection
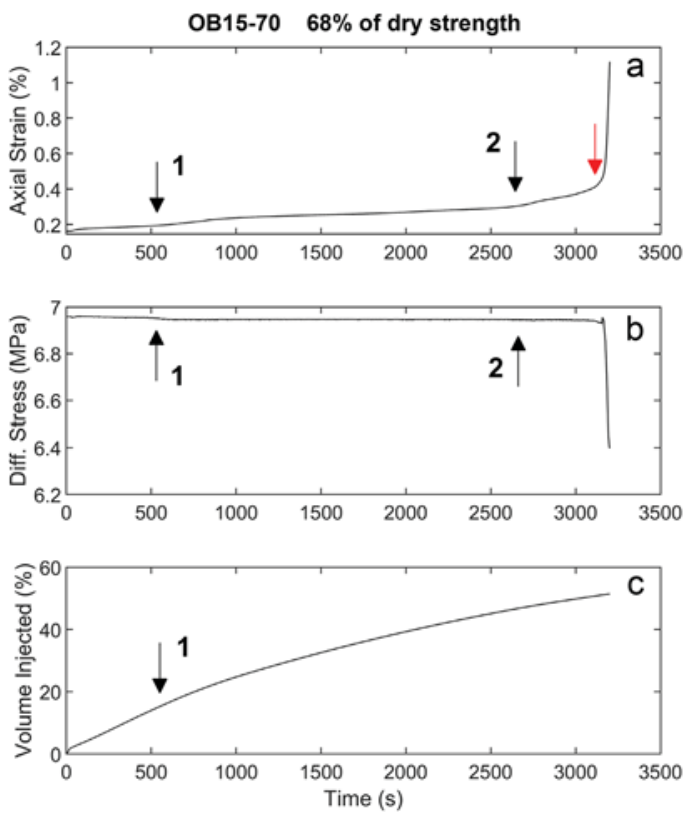

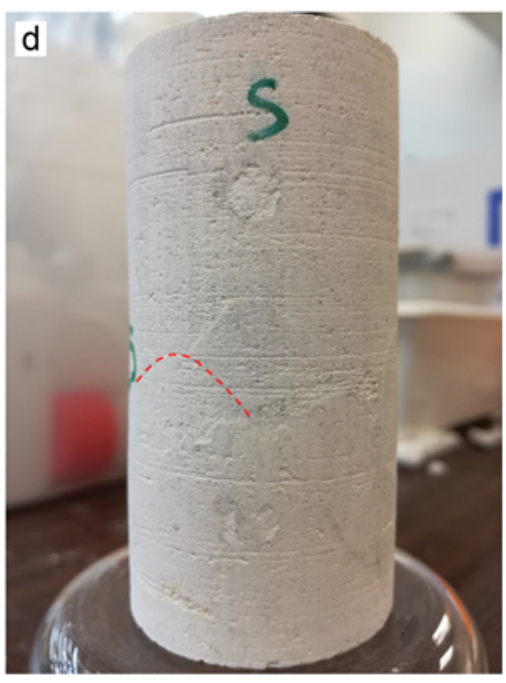

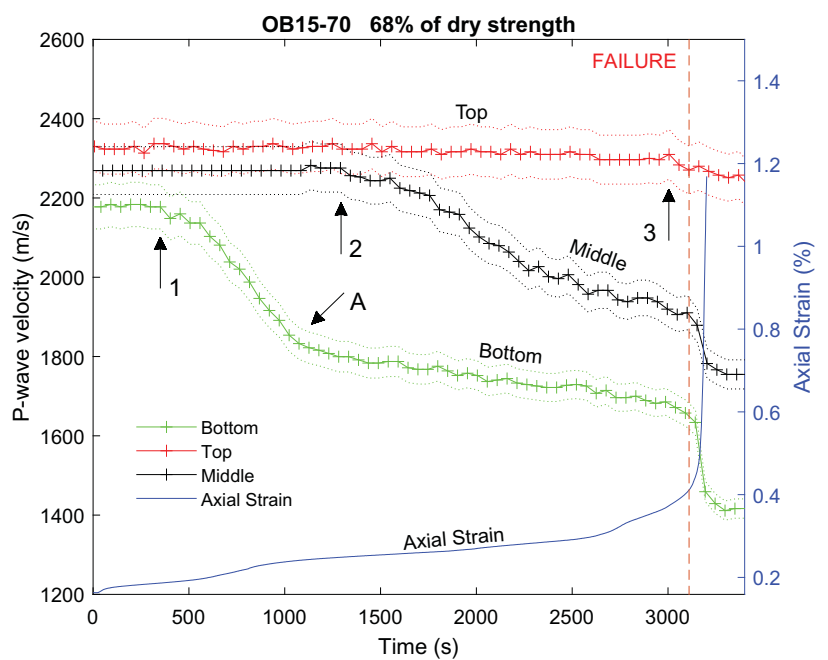

Fig. $13 \mathrm{P}$-wave velocity variation vs. time for injection test on sample OB15-70, $P_{\mathrm{C}}=1.5 \mathrm{MPa}$ and $Q=7 \mathrm{MPa}$. In blue is displayed the axial strain versus time. The velocity data are represented by crosses and the dotted lines depict the error which is on average $\pm 45 \mathrm{~m} / \mathrm{s}$

Furthermore, these features are observed only in the lower half of the sample, while the upper part seems undamaged.

Figure 13 shows the evolution of P-wave velocity measured in the three horizontal directions: bottom, midpoint and top during the injection. As the waterfront gradually rises upward, it induces a decrease in P-wave velocity, first at the bottom, then at the middle and finally at the top (events 1, 2 and 3 in Fig. 13). Besides water imbibition, the onset of inelastic deformation (observed at event 1 in Fig. 12) is a secondary contribution to the $\mathrm{P}$-wave velocity reduction which, however, took place just after the variation induced by the water and, for this reason, we could not discriminate it. Nevertheless, as observed in a standard imbibition test at room conditions (Fig. 11), once the waterfront reaches the plane where the ultrasonic transducers are located, the $\mathrm{P}$-wave velocity becomes stable with no further change. In contrast, we observe in Fig. 13 that after the strong velocity decrease, generated by the water rise, the velocity further decreases at point A with a lower slope, a manifestation of the ongoing rock deformation. Furthermore, the delayed arrival of the water front at point 3 (top) compared to point 2 (middle) in Fig. 13 shows that the ongoing deformation leads to a decrease of rock permeability.

At sample failure, a sharp velocity drop is observed only on the mid and bottom transducers planes with a higher drop in the latter, confirming that the damage is located only in the lower half of the sample, as visually observed in the post-mortem sample (Fig. 12d), while the water front just reached the upper transducers plane. In other words, the top of the sample was probably still dry at failure.

In Fig. $7 \mathrm{c}$ are also plotted the injection tests carried out at CSIRO, OB15-71 and OB15-74. The former shows similarities in the elastic behavior with the dry triaxial tests, whereas the residual strength post-mechanical instability reflects the behavior of the wet triaxial test. Indeed, the sample is initially dry during the loading stage whereas it is nominally saturated at the end of the test. However, the axial strain at failure is not correlated to the triaxial tests. In contrast, the injection test OB15-74 shows significant differences with respect to the triaxial tests, even if the axial strain at failure is similar. 


\section{For personal use}

Water-Induced Damage in Microporous Carbonate Rock by Low-Pressure Injection Test

\section{Discussion}

In the following paragraphs, we characterize the mechanical behavior, coupled with structural observations for the triaxial and injection tests. Thereafter, we propose a description of the parameters governing failure in the injection test. Finally, we discuss the water-weakening effect in terms of porosity and specific surface area.

\subsection{Structural Observations on Post Deformation Rock Samples}

Structural observations on both pre- and post-deformed rock samples were done to gain information about the tested material and the failure modes. Four lab-deformed samples have been cut perpendicular to the axial direction (i.e. perpendicular to the maximum stress) to prepare $30 \mu \mathrm{m}$-thick thin sections. Two of these selected samples have been deformed in dry condition in triaxial tests at $P_{\mathrm{c}}=2 \mathrm{MPa}$ and 4.5 MPa (samples OB20-D and OB45-D, respectively) and two in wet conditions at the same $P_{\text {c_eff }}$ (samples OB20$\mathrm{W}$ and OB45-D, respectively). The thin sections have been analysed with a petrographic microscope in polarized light and, a description of the observed features (e.g. fractures, deformation bands) is proposed. Figure 14a shows that sample OB20-D failed by the development of both deformation bands (1) and fractures (2). Looking closer to the deformation band (Fig. 14b), it appears like a narrow area of 200-300 $\mu \mathrm{m}$ in thickness, with an open crack in the middle and compacted areas on both sides with reduction in porosity. Baud et al. (2009) observed a similar feature in a SaintMaximin Limestone (SML) sample deformed at 5 MPa confining pressure, which was interpreted as a compactive shear band due the coupling between the compacting area and the macroscopic crack. In sample OB45-D (Fig. 14c), an evenly distributed deformation is observed with several compaction bands, although some open cracks are still present. In fact, three different features can be distinguished: (1) compaction bands, with only reduction in porosity; (2) compaction bands with an inner part where an open crack seems to develop/ initiate; (3) compactive shear bands. The thin sections for the sample deformed in wet conditions show similar attributes. In sample OB20-W ( $P_{\mathrm{C} \text { eff }}=2 \mathrm{MPa}$, Fig. $\left.14 \mathrm{~d}\right)$, compactive shear bands are formed albeit with a larger width of about $1 \mathrm{~mm}$. Moreover, this band depicts a symmetric change in gray levels going outward from the crack plane. In sample OB45-W $\left(P_{\mathrm{C}_{\text {eff }}}=4.5 \mathrm{MPa}\right.$, Fig. $\left.14 \mathrm{e}\right)$, the localized inelastic deformation is made of a widespread cataclasis composed by a tight network of compaction bands.

The X ray CT scans shown in Fig. 15a, b have been done on a sample triaxially deformed at $P_{\mathrm{c}}=1.5 \mathrm{MPa}$ in dry condition. The pre-deformation scan is shown for comparison
(Fig. 15a). The formation of an open fracture is well delineated with an angle of about $30^{\circ}$ with respect to the sample axis. It is also possible to distinguish in some area an increase in density around the fracture, (indicated by the arrows 1 and 2). This is well in line with our observations on thin sections, with the presence of a diffuse compactive band surrounding an open crack. The X ray CT scans of the water-saturated sample deformed at the same effective confining pressure (Fig. 15c, d), depict, once again, the formation of a discontinued open fracture with a denser part on both sides. Furthermore, in the upper part, a sub-horizontal fracture occurs (1 in Fig. 15d), with irregular surfaces that recalls a stylolite.

Our mechanical data show that starting from $P_{\mathrm{c} \_ \text {eff }}=1 \mathrm{MPa}$, the behavior in the wet experiments is characterized by shear-enhanced compaction, which is confirmed by this sections observation (localized structures in samples OB20-D and OB20-W). This behavior is typical of the transition from brittle to ductile regimes (Wong and Baud 2012) with the formation of localized shear bands. The observed damage seems to develop as follow: first, the grains undergo crushing and rotation producing compaction surfaces, then, when the porosity is reduced of a critical level in these areas, a macroscopic open crack is formed, generating the observed stress drop. Furthermore, the micrograph depicted in Fig. 14f (sample OB45-D) shows that the grain crushing and cracking involves the rock matrix, while the stiffer microfossil shell remains unaffected. The mechanical data showed by Baud et al. (2009) on Saint-Maximin Limestone (37\% of porosity) display the same kind of stress drops as we observed here in Obourg Chalk. Baud et al. (2004, 2017) linked the occurrence of these stress drops to the production of compaction localizations in the sample, and the formation of several deformation bands. Hence, we consider the behavior observed in our mechanical tests between $P_{\text {c_eff }}=0.5 \mathrm{MPa}$ and $2 \mathrm{MPa}$ as belonging to the brittle-ductile transition or transitional regime (Wong et al. 1997). The plateau in the mechanical data after the yield and coexisting with peak stresses also seems to indicate a transitional regime (Wong and Baud 2012).

At $P_{\text {c_eff }}=4.5 \mathrm{MPa}$, the differential stress-axial strain curve in dry and wet conditions show once more a stabilization beyond the yield stress, whereas the stress drops disappear. In addition, looking at the thin sections, even if the deformation seems to be homogeneously distributed in the sample, it is, however, localized in multiple structures. This is distinctively shown in the dry tested sample (Fig. 14c) but also in the water-saturated tested sample (Fig. 14e). Indeed, the sample OB45-W is pervaded by several compactive bands of about $100 \mu \mathrm{m}$ in thickness, rather than a homogeneous cataclastic flow, whereas, the areas between those bands seem to remain undamaged. The absence of stress drops at $P_{\mathrm{c} \_ \text {eff }}$ higher than $2 \mathrm{MPa}$ may be due to the higher confining 


\section{For personal use}

D. Geremia et al.
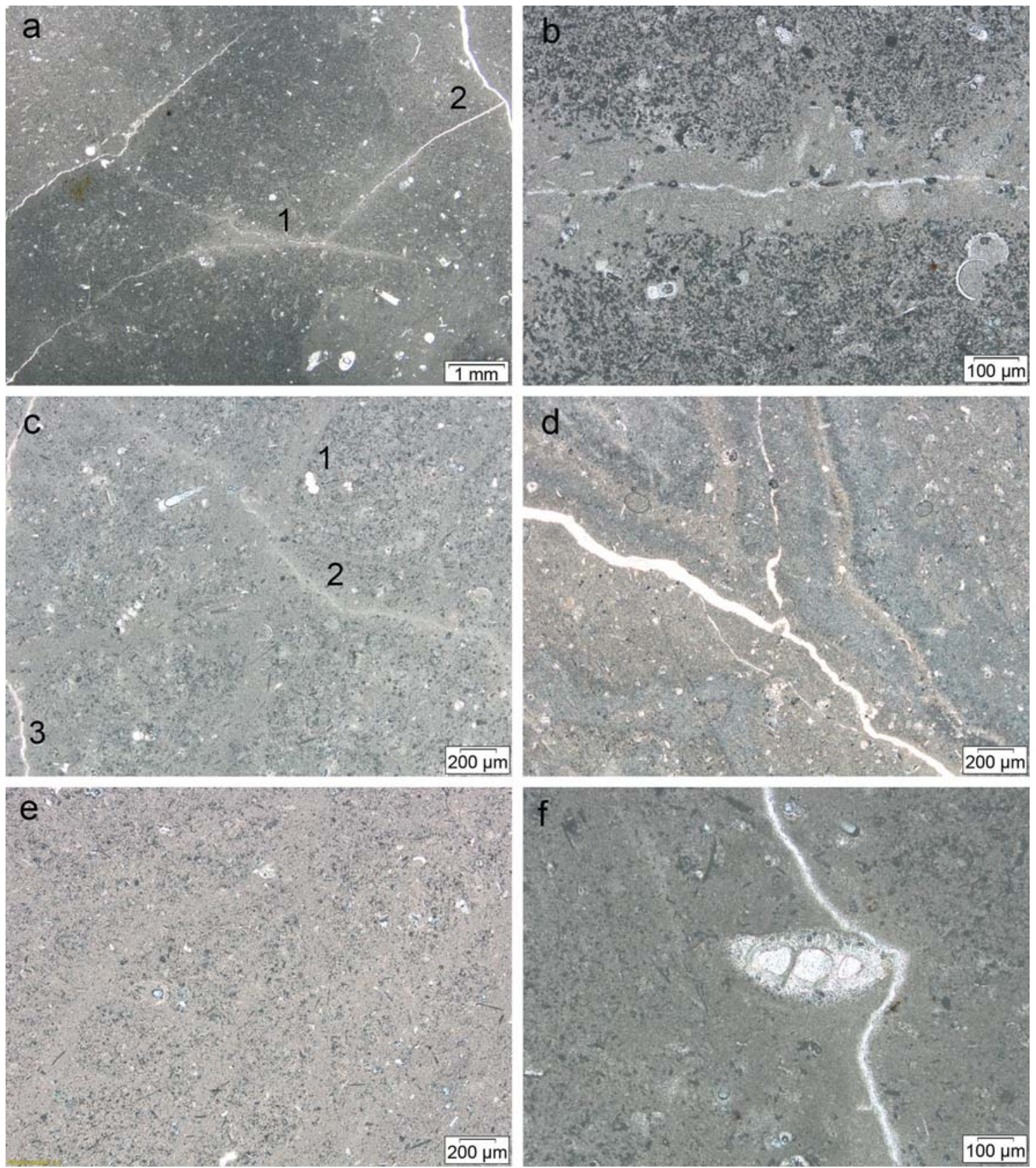

Fig. 14 Series of micrographs from thin sections on post-deformation Obourg chalk samples taken perpendicular to the sample axis. The numbers represent features described in the text: $\mathbf{a}-\mathbf{b}$ dry triaxial

pressure that inhibits the formation of shear fractures; hence, once one compaction band is formed, deformation moves to other areas. It is important to emphasize that no intent was done to study the plastic deformation possibly experienced during our mechanical tests since the very low grain size makes it difficult to observe. Keeping that in mind, the relatively undamaged areas might have experienced plastic deformation that we were not able to observe, while the grain crushing and rotation might have been localized in test at $P_{\mathrm{C}}=2 \mathrm{MPa}$ (OB20_D); $\mathbf{c}, \mathbf{f}$ dry triaxial test at $P_{\mathrm{C}}=4.5 \mathrm{MPa}$ (OB45_D); d wet triaxial test at $P_{\mathrm{C}}=2 \mathrm{MPa}\left(\mathrm{OB} 20 \_\mathrm{W}\right)$; e wet triaxial test at $P_{\mathrm{C}}=4.5 \mathrm{MPa}\left(\mathrm{OB} 45 \_\mathrm{W}\right)$

high-density structures more easily detectable. Nevertheless, the mechanical data of the sample at $P_{\mathrm{c}}=11 \mathrm{MPa}$ manifest strain hardening, typical of a ductile regime.

These observations support a continuous evolution with increasing confining pressure, from dilatancy, to localized deformation in few structures, to pervasive localized compaction and, ideally, at higher confining pressure, toward a homogeneous cataclastic flow. These results are well consistent with the previous study on porous carbonate rocks 


\section{For personal use}

Water-Induced Damage in Microporous Carbonate Rock by Low-Pressure Injection Test
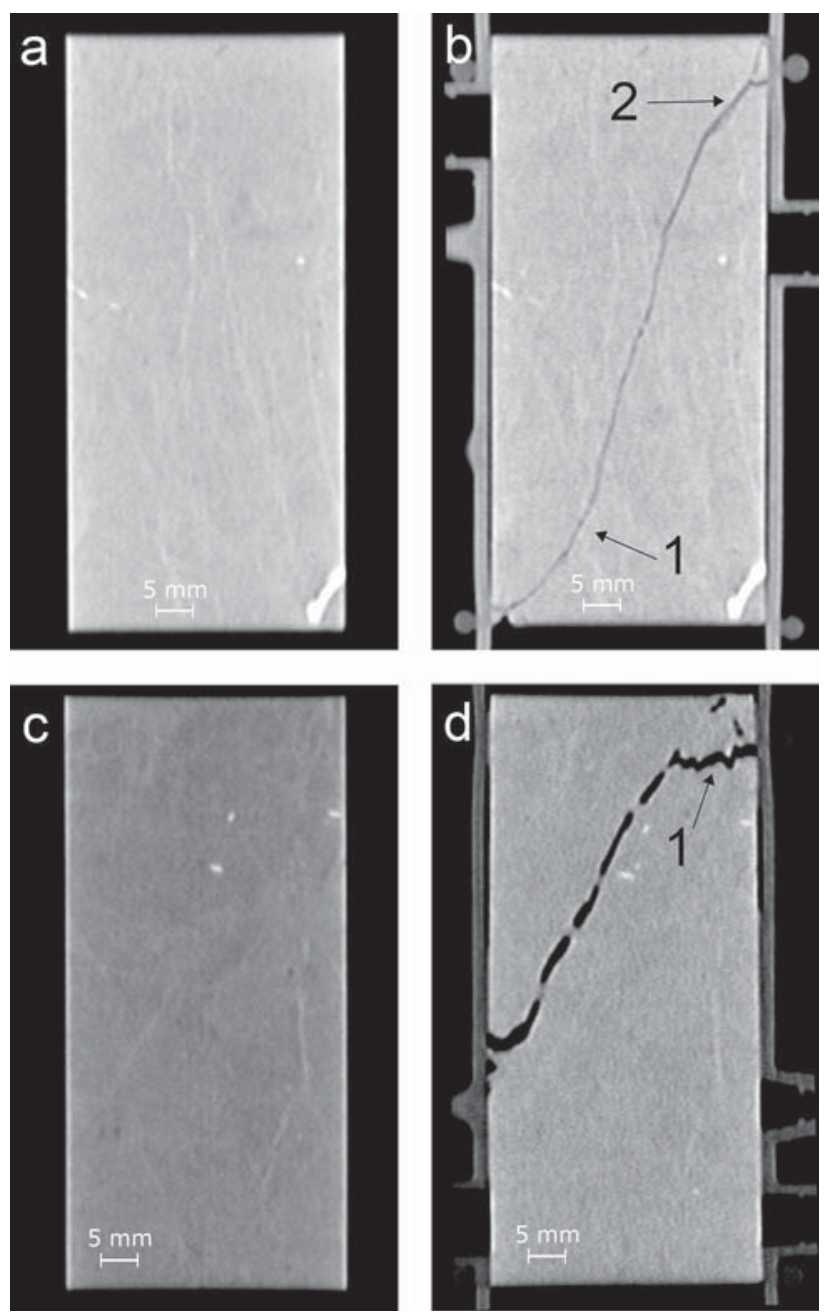

Fig. 15 Pictures in grayscale displaying slices of CT-scan performed on Obourg chalk samples at CSIRO, taken parallel to the sample axis. High intensity $=$ dense. The arrows represent features described in the text: $\mathbf{a}-\mathbf{b}$ CT scan on pre (a) and post (b) triaxial test performed at $P_{\mathrm{C}}=1.5 \mathrm{MPa}$ in dry condition; $\mathbf{c}-\mathbf{d} \mathrm{CT}$ scan on pre (c) and post (d) triaxial test performed at $P_{\mathrm{C}}=1.5 \mathrm{MPa}$ in water-saturated condition

(Homand and Shao 2000; Baud et al. 2009, 2017; Han et al. 2016). Moreover, Obourg chalk has a very low brittle to ductile transition compared to other carbonate rocks.

\subsection{Microstructures Resulting from Injection Tests}

Microstructural studies were also performed on samples that experienced injection tests. Figure 16 shows the microCT Scans, done at IFP Énergies Nouvelles (IFPEN) after three injection tests. Figure 16a displays the sample OB15-75 tested at $Q=7.5 \mathrm{MPa}$ and $P_{\mathrm{c}}=1.5 \mathrm{MPa}$, just below the yield envelope in dry condition. The scan shows the presence of a high-density compactive area forming a conical shape in the bottom part of the sample. Moreover, a more developed feature, on the right side of the scan, departs from this cone with successive low- and high-density zones propagating up to the middle of the rock sample. Note that the upper half of the sample seems to be completely undamaged. These observations agree with the mechanical data showing that the sample failed when only $13 \%$ of the pore volume has been flushed by water, meaning that necessarily the water was located only in the lower part of the rock specimen. Figure $16 \mathrm{~b}$ shows a slice in the damaged part, perpendicularly to the axis as shown in Fig. 16a. The conical damaged zone is made of several curved bands (e.g. white arrows) which, in some cases, propagate toward the surfaces forming radial features. Such type of deformation with multiple radial fractures has been observed also by David et al. (2015b) on Sherwood sandstone samples after injection tests, following the same experimental methodology, and by Batiste et al. (2004) and Desrues et al. (1996) on a sand pack deformed in triaxial experiments. The similarity between these observations lead David et al. (2015b) to interpret such features as due to a loss of cohesion between the grains in the waterinvaded part.

Figure $16 \mathrm{c}$ corresponds to a microCT scan on sample OB15-65 deformed at $Q=6.5 \mathrm{MPa}$ and $P_{\mathrm{c}}=1.5 \mathrm{MPa}$, just above the peak stress in wet condition. In this experiment, deformation is widespread over the entire sample, with a thick diffuse band of maximum width $10 \mathrm{~mm}$ and conical damaged structures in both the bottom and the top. The sample failed when the amount of injected water exceeded $100 \%$ of the pore volume, in good agreement with the structural observations. Aside the damage location, this test differs from the previous one in the deformation type of the conical feature which is composed of a set of open fractures. Furthermore, the diffuse band in Fig. 16d is bordered by open cracks which formed after the compactive bands.

Finally, increasing the confining pressure to $4 \mathrm{MPa}$ and the differential stress to $8.5 \mathrm{MPa}$ just below the dry yield envelope like OB15-75, sample OB40-85 presents similar features as OB15-75. In this case, the water volume needed to induce failure was equal to $10.5 \%$ of the pore volume and, as expected, damage is only located in the lower half of the rock sample (Fig. 16e, f). In contrast, the overall damage experienced by the sample is associated with the merging of multiple bands giving rise to an evenly distributed cataclasis. The evolution of the failure mode with increasing effective confining pressure in the injection tests seems, moreover, to be very similar to what has been observed in the triaxial tests: going from $P_{\mathrm{c}}=2 \mathrm{MPa}$ to $4.5 \mathrm{MPa}$, the number of bands generated during the damaging increased, leading to a homogeneously distributed deformation.

The injection tests performed at CSIRO (mechanical data displayed in Fig. 7c) present differences and similarities with respect to the ones done at CYU. First, the sample OB1574 tested at $P_{\mathrm{c}}=1.5 \mathrm{MPa}$ and $Q=7.4 \mathrm{MPa}$ (Fig. 17a, b) does not show any conical damaged structure near the edge 


\section{For personal use}

D. Geremia et al.

Fig. 16 Pictures in grayscale displaying slices of $\mu \mathrm{CT}$-scan performed on Obourg chalk samples at IFPEN, taken parallel and perpendicular to the sample axis. High intensity $=$ dense. The arrows represent features described in the text: $\mathbf{a}-\mathbf{b}$ parallel and perpendicular slice on sample OB15-75 post-injection test (stress state: $P_{\mathrm{C}}=1.5 \mathrm{MPa}$, $Q=7.5 \mathrm{MPa}$ ); c-d parallel and perpendicular slice on sample OB15-65 post-injection test. Stress state: $P_{\mathrm{C}}=1.5 \mathrm{MPa}$, $Q=6.5 \mathrm{MPa}$; e-f Parallel and perpendicular slice on sample OB40-85 post-injection test. Stress state: $P_{\mathrm{C}}=4 \mathrm{MPa}$, $Q=8.5 \mathrm{MPa}$
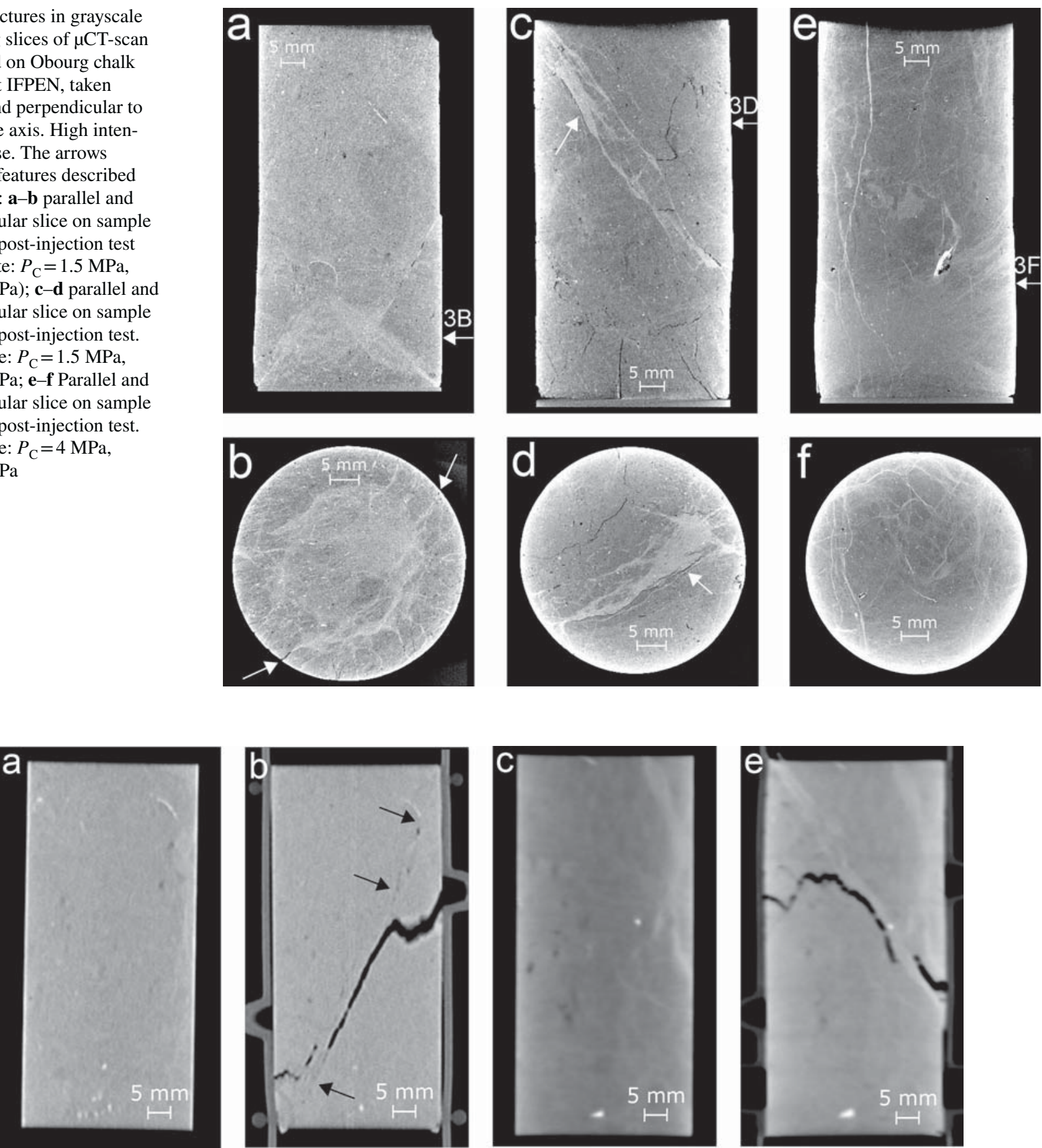

Fig. 17 Pictures in grayscale displaying slices of CT-scan performed on Obourg chalk samples at CSIRO, taken parallel to the sample axis. High intensity $=$ dense. The arrows represent features described in the text: a-b CT-scan on sample OB15-74 pre (a) and post (a) injec-

of the sample. Moreover, the deformation seems to involve the entire sample even if the water injected at failure was $47 \%$ of the pore volume. Nevertheless, the highest damage is located in the lower half of the sample, with the presence of an open fracture that seems to border the thin deformation band that affects the entire sample at about $30^{\circ}$ with respect tion test performed at $P_{\mathrm{C}}=1.5 \mathrm{MPa}$ and $Q=7.4 \mathrm{MPa}$; $-\mathbf{d}$ CT-scan on sample OB15-71 pre (c) and post (d) injection test performed at $P_{\mathrm{C}}=1.5 \mathrm{MPa}$ and $Q=7.1 \mathrm{MPa}$

to the sample axis (black arrows in Fig. 17b). Figure 17c, d shows the CT scans of sample OB15-71 tested at the same confining pressure but at $Q=7.1 \mathrm{MPa}$. In this case, the water injected at failure was $114 \%$ of the pore volume and the damage is mostly located in the middle-upper region. Once again, it is composed by a diffuse band bounded by open 
fractures on both sides, generating a damage very similar to the one observed in OB15-65 (Fig. 16c).

In contrast to the compactive behavior delineated by the triaxial tests at confining pressures higher than $P_{\mathrm{c}}=0.5 \mathrm{MPa}$, the injection test OB15-74 (Fig. 18) shows that while undergoing shear-enhanced compaction, it is also subjected to an opposite evolution in the porosity change (blue curve in Fig. 18). The stress state at this point is referred in the literature as the critical stress $\mathrm{C}^{\prime} *$ (Wong and Baud 2012). In fact, the majority of the injection tests reached a total axial strain higher than $3 \%$, which is much higher than the maximum axial strain attained in the triaxial tests $(0.8 \%)$. For both injection tests performed at CSIRO, the volumetric strain exhibits first a compactive behavior that switches, when the sample is failing, to

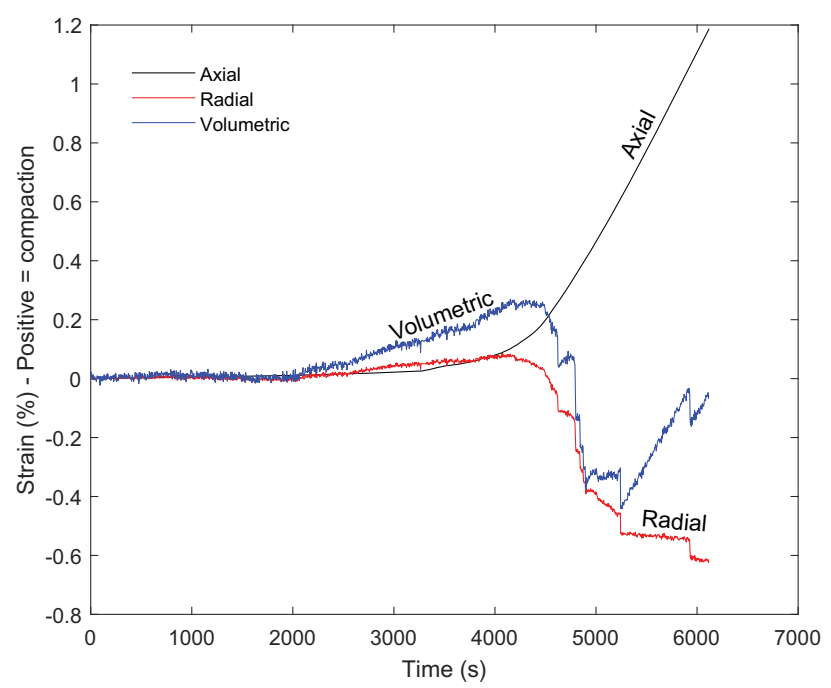

Fig. 18 Axial, radial and volumetric strain plotted in function of time from injection test on sample OB15-74 $\left(\mathrm{P}_{\mathrm{C}}=1.5 \mathrm{MPa}, \mathrm{Q}=7.4 \mathrm{MPa}\right)$

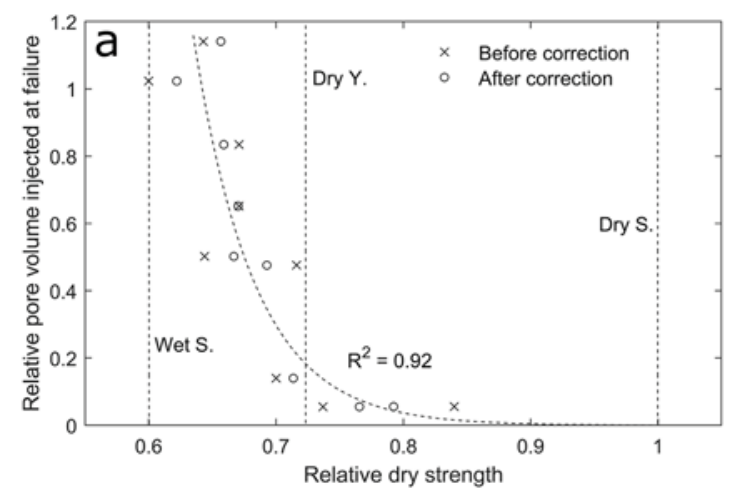

Fig. 19 a Compilation of volume injected at failure (normalized with respect to the sample pore volume) plotted versus the relative dry strength for injection tests performed at CYU and CSIRO. With black crosses are represented the data with no porosity correction applied, black circles are the same data with the correction. The dry strength dilatancy which may be identified in the open fractures bonding the compaction band. Furthermore, in the test OB15-74, the volumetric strain shifts again to porosity reduction when the radial strain variation ceases (Fig. 19). However, this latter observation must be taken with caution because a local radial measurement might be strongly impacted by the fracture localization.

In summary, the failure modes and the damage produced in both triaxial and injection tests at low confining pressure seem comparable. The higher damage observed in the injection tests arises from the experiment itself, i.e. as in a brittle creep test, it results from a higher total strain accumulated at the end of the test. Such differences were also observed by Brantut et al. (2013), comparing creep and triaxial experiments on Darley Dale sandstone (Heap et al. 2009). The complex damage features, like the conical fractured area, might just be an artefact due to the friction at the sample-piston interface, since it is not (or just slightly) observed, in the test conducted with the ATC at CSIRO. Nevertheless, it is clearly demonstrated that water induces a strong weakening with probably loss of cohesion (David et al. 2015b) in the water-invaded area. Then, as a second order effect, the experimental setup could influence more or less the location of the produced damage. Apart from the injection tests performed at a stress state close or above the yield point, in which only a little amount of injected water is enough to induce failure, the damage generally affects the overall rock specimen but with a higher intensity in the water-invaded zone. Therefore, even though water is located in the lower half of the sample, the strength might depend on both parts: the dry and the water-invaded zones. A critical saturation is then necessary to trigger the mechanical instability, which depends on the stress applied on the rock sample. The relationship between the amount of water injected respect to the pore

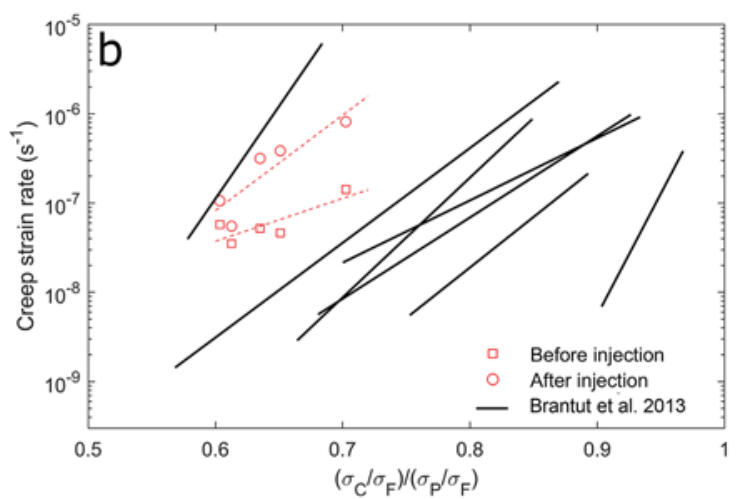

(Dry S.) and yield (Dry Y.) and the wet strength (Wet S.) are displayed for comparison. $\mathbf{b}$ Creep rate before and after injection derived from the injection tests conducted at $\mathrm{CYU}$ at $\mathrm{P}_{\mathrm{C}}=1.5 \mathrm{MPa}$, compared with the literature data (Brantut et al. 2013) 
volume at failure and the stress state of the injection tests is discussed in the next section.

\subsection{Effect of Waterflooding on Mechanical Strength}

Generally, all the injection tests exhibit the same behavior. In Table 3, we compiled all the critical parameters derived from these tests: stress state, porosity and water injected at failure. Two of these parameters were selected to characterize the mechanical failure induced by water flooding in Obourg chalk: the amount of water injected at failure (normalized to the sample pore volume) and the stress state (Q). From the mechanical data obtained from triaxial tests conducted on dry samples at $P_{\mathrm{c}}=1.5 \mathrm{MPa}$, we observed the following relationship between peak stress $\left(\sigma_{\mathrm{P}}\right)$, expressed in $\mathrm{MPa}$, and porosity $(\phi)$, expressed in fraction:

$\sigma_{\mathrm{P}}=-26.51 \phi+22.19$

As this equation does not show a good fitting (chisquare $=3$, giving an error to the peak stresses of $0.3 \mathrm{MPa}$ ), it is worth mentioning that we only use it in a narrow porosity range between 0.42 and 0.44 . Through this equation, we first extrapolated the peak stresses for the samples tested in the injection tests according to their porosity and then, we normalized the applied differential stress to the respective strength, obtaining the relative dry strength corrected with respect to the porosity. Figure 19a shows the injected pore volume at failure correlated to the relative dry strength for the injection experiments performed at $P_{\mathrm{c}}=1.5 \mathrm{MPa}$. In the figure, two set of data are displayed, representing the data with and without the porosity correction (Eq. 8). Clearly, the correction causes a reduction in scattering as the corrected data follow a better trend $\left(R^{2}=0.92\right)$. This shows that the scattering is mainly associated with the porosity variability and that Eq. 8 captures this effect accurately. For both curves, the volume of water necessary to induce mechanical instability decreases exponentially with respect to the differential stress. From the corrected dataset, considering the normalized parameters $Q_{\mathrm{r}}$ the ratio between applied differential stress and dry strength, and $V_{\mathrm{r}}$, the ratio between injected water volume at failure and total pore volume, the following empirical relationship was found:

$V_{r}=A \exp \left(-\frac{Q_{r}}{Q_{o}}\right)$

with experimental parameters $A=6.910^{5}$ and $Q_{0}=0.0477$. Furthermore, the most significant change occurs at stress states lower than the yield dry values $(\sim 0.72$ of relative dry strength). This means that, as soon as we approach the yield stress point, the cracks start to form even without water and the injection of few percentage would quickly promote their propagation. Hence, at differential stress higher than the yield, the injection of a small amount of water representing only few percents of pore volume is enough to trigger the sample failure.

At this point, one can argue that the relationship between the water injected at failure and the differential stress (Fig. 19a) might be due to the fact that the effect of water in producing weakening is only linked to an increase in the creep rate reducing the time to have failure; hence, is the failure just a matter of total strain that the rock can support or does the saturation level play a role?. We compared in Fig. 19b the creep strain rates of the injection tests performed at $P_{\mathrm{c}}=1.5 \mathrm{MPa}$ and conducted at CYU with a compilation of data from Brantut et al. (2013). In this figure, the strain rate is plotted as a function of the normalized stress $\sigma^{*}$ which is given by:

Table 3 Critical parameters from injection tests conducted in this study

\begin{tabular}{lllllll}
\hline Sample name & $\begin{array}{l}\text { Differential } \\
\text { stress (MPa) }\end{array}$ & $\begin{array}{l}\text { Confining pres- } \\
\text { sure (MPa) }\end{array}$ & $\begin{array}{l}\text { Effective mean } \\
\text { stress (MPa) }\end{array}$ & $\begin{array}{l}\text { Relative dry } \\
\text { strength corrected }\end{array}$ & Porosity (\%) & $\begin{array}{l}\text { Water inj. at failure } \\
\text { respect to pore } \\
\text { volume }\end{array}$ \\
\hline OB12-84 & 8.4 & 1.2 & 4 & 0.79 & 43.7 & 0.06 \\
OB15-65 & 6.5 & 1.5 & 3.7 & 0.62 & 44.3 & 1.02 \\
OB15-70 & 7 & 1.5 & 3.8 & 0.67 & 44.1 & 0.5 \\
OB15-71 & 7.1 & 1.5 & 3.9 & 0.66 & 42.8 & 1.14 \\
OB15-73A & 7.3 & 1.5 & 3.9 & 0.67 & 42.9 & 0.65 \\
OB15-73B & 7.3 & 1.5 & 3.9 & 0.66 & 42.2 & 0.83 \\
OB15-74 & 7.4 & 1.5 & 4 & 0.7 & 43.5 & 0.48 \\
OB15-75 & 7.5 & 1.5 & 4 & 0.71 & 42.3 & 0.14 \\
OB20-84 & 8.4 & 2 & 4.8 & 0.77 & 43.7 & 0.06 \\
OB40-70 & 7 & 4 & 6.3 & 6.8 & - & 43.6 \\
OB40-85 & 8.5 & 4 & & & & 0.54 \\
\hline
\end{tabular}




\section{For personal use}

Water-Induced Damage in Microporous Carbonate Rock by Low-Pressure Injection Test

$\sigma^{*}=\frac{\left(\sigma_{\mathrm{C}}-\sigma_{\mathrm{F}}\right)}{\left(\sigma_{\mathrm{P}}-\sigma_{\mathrm{F}}\right)}$

where $\sigma_{\mathrm{C}}$ is the applied differential stress, $\sigma_{\mathrm{P}}$ the compressive strength and $\sigma_{\mathrm{F}}$ the frictional strength. The latter is computed using the Coulomb's criterion and considering a friction coefficient equal to 0.52 , derived using the sliding wing crack model (Cotterell and Rice 1980; Ashby and Sammis 1990) on the triaxial tests in dry conditions at low confining pressure. As the applied differential stress increases, $\sigma^{*}$ approaches unity. We note that the strain rates before the injection display higher values than other rocks type at the same stress state, even if, the sensitivity with the differential stress is small. In contrast, after the injection, the creep strain rates undergo an increase of up to 1 order of magnitude, showing also a higher sensitivity with respect to the differential stress. Nonetheless, in brittle creep experiments, tertiary creep generally only initiates when a critical level of inelastic strain is reached (Kranz and Scholz 1977; Baud and Meredith 1997), which marks the initiation of damage localization. The total axial strain reached by the injection tests conducted at $P_{\mathrm{c}}=1.5 \mathrm{MPa}$ does not show a clear correlation with the stress state, which might be also due to the mechanical variability of this chalk. Hence, even if the injection of water induces a higher strain rate as the applied differential stress increases (Fig. 19b), this might not be the cause of the reducing time of failure if different rock samples fail at different strain level. Nevertheless, more experiments are required to clarify this concept.

Generally, the fluid sensitivity of the strain rate has been associated to a stress corrosion at the tip of cracks which enhances the subcritical crack growth (Brantut et al. 2013). This happens because of the adsorption of water onto the grain surface which can decrease the surface energy, and so the fracture toughness. Moreover, the chemistry of the fluid can have a strong impact on the creep rate and in general on the mechanical resistance. Risnes et al. (2003) demonstrated through mechanical experiments on Liège chalk that the yield stress and the tensile strength are influenced by the dissolved salt in the involved fluid. They stated that the weakening is governed by the water activity, which decreases by increasing the salt content. Madland et al. (2011) also showed how the injection of water with different dissolved salts has a different impact on the mechanical stability of Liège chalk and Stevns Klint chalk. They observed an enhancement of the weakening when water containing $\mathrm{MgCl}_{2}$ or seawater were injected and, they discussed a substitution between calcium and magnesium due to dissolution and mineral precipitation as the dominant mechanism. We used in the present work a single fluid (tap water) and, for this reason, more work is needed to highlight the effect of fluid chemistry which is beyond the scope of this paper. Preliminary results from uniaxial compressive tests on the studied chalk showed that the weakening is strongly influenced by the chemical species and slightly by the salt concentration.

Homand and Shao (2000), through experimental tests of water injection into oil-saturated sample, stated that exists a critical water saturation after which a sudden transition between two different mechanical behavior occurs. In the same scenario, by considering the relative pore volume injected at failure (Fig. 19a) as water saturation, it might be stated that the rock strength decreases progressively with increasing the saturation. A similar decrease in mechanical resistance with water saturation has been also observed by Risnes et al. (2005) on Liège Chalk by means of mechanical experiments varying the fluid saturation with a mixture of water and ethylene glycol. Indeed, they observed on hydrostatic, triaxial and Brazilian tests that the strength decreases with increasing the Mole \% of water with a major change in the first percentages of water saturation. Røyne et al. (2011) through double torsion experiments on calcite, also noticed the same kind of trend in the variation of the surface energy, which is defined as the half of the work necessary to cut a solid body in two new surfaces, with respect to the fraction of water adsorbed onto the surface. They observed indeed, from dry to wet condition a decrease from 0.32 to $0.15 \mathrm{~J} / \mathrm{m}^{2}$.

\subsection{Mechanisms of Water-Weakening}

Applying the observation of Røyne et al. (2011) on calcite mineral surface to rock, the weakening might be induced by the water that, adsorbing onto the grain surface, decreases the energy to develop cracking. In this scenario, water should have a strong mobility in the rock pore network because, to promote fracturing, it should be always present at the crack tips while these are advancing. These observations can also apply to the triaxial tests done on Obourg Chalk where in the tests in wet condition, the stress drops seem to be reduced in frequency and attenuated in amplitude. This could be ascribed to the fact that when fracturing, water is not capable to quickly follow the process zone at the crack tip, which remains dry. Doing so, the fracture propagation would be inhibited because of the applied differential stress which is much lower than the strength in dry condition. This could also explain the difference in deformation between the dry and wet tests performed at $P_{\text {c } \_f f}=4.5 \mathrm{MPa}$.

Baud et al. (2000) introduced the parameter $\lambda$ as the ratio between the surface energies in wet $\left(\gamma^{\prime}\right)$ and dry $(\gamma)$ conditions and explained that, in the Hertzian fracture model (Zhang et al. 1990a, b) the ratio between the critical pressures $P^{*}{ }_{\text {wet }}$ and $P^{*}$ dry is related to $\lambda$ in the following way: 
$\frac{P_{\text {wet }}^{*}}{P_{\text {dry }}^{*}}=\left(\frac{\gamma^{\prime}}{\gamma}\right)^{3 / 2}=\lambda^{3 / 2}$

Using our $P^{*}$ values, we obtain a surface energies ratio $\lambda$ of 0.63 which is higher compared to the value derived by Røyne et al. (2011) on calcite (0.47). A compilation of $\lambda$ values from previous studies on carbonate rocks and sandstones is shown in Fig. 20a. Most of them have been derived from the critical stresses $P^{*}$ in wet and dry condition. For the Tavel limestone, Nicolas et al. (2016) obtained $\lambda$ from the fracture toughness acquired using the sliding wing crack model (Cotterell and Rice 1980; Ashby and Sammis 1990). David et al. (2015b), by contrast, calculated $\lambda$ for Sherwood sandstone from the strength reduction in triaxial experiments in dry and wet conditions. A linear evolution was found when plotting $\lambda$ vs porosity $\phi$ :

$\lambda=a-b \phi$

with experimental parameters $a=1.009$ and $b=0.826$. This trend is, nevertheless, totally expected. Indeed, besides considering the surface really in contact with water, as the porosity increases so does the amount of water, which is reflected in an increased weakening. Furthermore, we can note that the intercept of the linear regression is 1 at porosity 0 as no weakening is expected when porosity (thus water) is absent. Apart the general trend, it seems that the data can be clustered in three different groups depending on porosity $(11-21 \%, 30-37 \%, 42-44 \%)$ where each of these show locally an opposite trend with respect to the previous one, where the weakening decreases with increasing porosity. It is hence clear that porosity plays a primary role in the water-weakening but, other parameters must have a

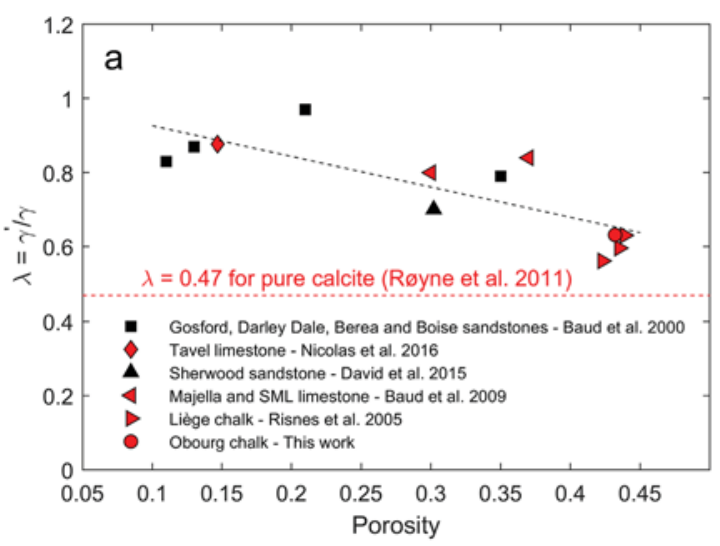

Fig. 20 a Compilation of $\lambda$ parameters plotted versus porosity for different rocks obtained from the literature. Each symbol represents a different source of data and carbonate rocks are depicted with solid red symbols; $b$ Compilation of $\lambda$ plotted in function of the specific secondary influence, like the pore shape and size, the grain size, as well as the rock mineralogy and the fluid chemistry. To highlight this, we computed the specific surface area of Obourg chalk and Tavel limestone by assuming the bulk rock being composed of spherical grains of diameter 0.00158 and $0.005 \mathrm{~mm}$ (Nicolas et al. 2016), respectively, and considering the grain density of calcite $\left(2720 \mathrm{~kg} / \mathrm{m}^{3}\right)$. Moreover, using the values reported by Risnes et al. (2005) for Liège Chalk, by Baud et al. (2009) for Majella and SaintMaximin limestones (SML) and by Lai and Krevor (2014) for Berea sandstone, obtained through BET method, we produced the graph in Fig. 20b, where the specific surface area is related to $\lambda$. It appears clear that the weakening depends on the water-grains contact area. Furthermore, rocks containing only calcite seem to fall in a good linear trend with a high $R^{2}=0.92$, whereas sandstones and SML (61\% calcite and 39\% quartz, Baud et al. 2009) for a given surface area, display a lower weakening which can be explained by the different mineralogy which in turn might behave differently with respect to calcite in terms of surface energy reduction. Moreover, the presence of clay in Berea sandstone might add further complications due to their swelling nature.

\section{Conclusion}

We have investigated the water-weakening effect on Obourg Chalk by means of conventional mechanical tests and injection tests. The mechanical behavior shows that it deforms in brittle condition only at very low $P_{\mathrm{c}}$. A transitional regime is observed over a wide range of confining pressures, with the development of compaction localizations increasing until a homogeneous cataclasis is produced at $P_{\mathrm{c}}$ above $4.5 \mathrm{MPa}$.

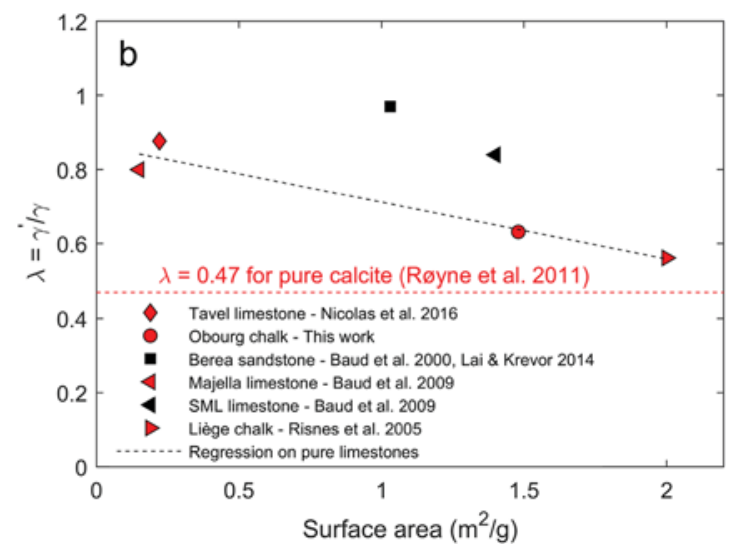

surface area. In red are shown the carbonate rocks whereas in black the sandstones and limestone containing quartz (e.g. Saint-Maximin limestone) 


\section{For personal use}

Water-Induced Damage in Microporous Carbonate Rock by Low-Pressure Injection Test

Water has a strong effect on this highly porous carbonate rock, resulting in a reduction of about $50 \%$ in the mechanical strength $\left(P^{*}{ }_{\text {wet }} / P^{*}{ }_{\text {dry }}=0.5\right)$. Moreover, it seems that water also inhibits the development of the episodic stress drops observed in dry conditions probably because it promotes grain crushing and rotation rather than shear fractures.

It is shown that injecting water at very low pressure, into a dry sample triaxially loaded at differential stress lower than yield in dry condition, led the sample to fail. Furthermore, a critical saturation is required to trigger deformation and failure. This critical water saturation, moreover, displays an exponential trend with respect to the differential stress applied on the rock specimen, hence, it strongly depends on how far the stress state is from the failure envelope. The injection of water induces a deformation comparable to the conventional triaxial tests. Even if it is more developed and diffused in the water-invaded zone, damage also propagates in the dry areas, suggesting that a mechanical coupling between the saturated and dry part might control the failure.

Beside all the possible weakening mechanisms, porosity and, in particular the surface area, are among the main controlling parameters, hence, further studies are necessary to unravel their role.

Our results can have a strong impact on waterflooding, EOR and EGS operations, since replacing the in-situ fluid with a foreign one could induce a significant damage, which would lead to a decrease in reservoir transmissivity, hence reducing considerably the production and lifetime of reservoirs. Furthermore, our results would also have an impact in geotechnical issues, since water-weakening is known to play a major role on surface subsidence induced by the collapse of underground cavities.

Acknowledgements We thank Nicolas Gland and Elisabeth Rosenberg (IFPEN Rueil-Mailmaison) for their fruitful discussions about this work; Damien Bury (Université de Mons) for his help in sampling Obourg chalk; Roua Al Houmaissi for the work conducted during her master internship at CYU and David Nguyen, Ludwig Monmusson, Shane Kager (CSIRO) for their precious help in testing the material of this work.

Funding This work has been supported by the Doctoral School of the Cergy Paris Université and by the $\mathrm{GEO}^{2} \mathrm{FRI}^{2} \mathrm{SK}$ project granted by the Paris-Seine Initiative. The authors also acknowledge the European Regional Development Fund (through the Interreg V FWVl programme) and Wallonia for funding the RISSC project in which this study is included.

Availability of Data and Materials The presented data collected through experiments conducted by the authors are stored in the database of Cergy Paris Université and can be made available upon request.

\section{Compliance with Ethical Standards}

Conflict of Interest The authors declare no conflict of interests.

\section{References}

Ashby MF, Sammis CG (1990) The damage mechanics of brittle solids in compression. Pure Appli Geophys PAGEOPH. https://doi. org/10.1007/BF00878002

Batiste SN, Alshibli KA, Sture S, Lankton M (2004) Shear band characterization of triaxial sand specimens using computed tomography. Geotech Test J. https://doi.org/10.1520/gtj12080

Baud P, Meredith PG (1997) Damage accumulation during triaxial creep of Darley Dale sandstone from pore volumometry and acoustic emission. Int J Rock Mech Mining Sci Geomech Abstr. https://doi.org/10.1016/S1365-1609(97)00060-9

Baud P, Zhu W, Wong T (2000) Failure mode and weakening effect of water on sandstone. J Geophys Res Solid Earth. https://doi. org/10.1029/2000jb900087

Baud P, Klein E, Wong T, fong, (2004) Compaction localization in porous sandstones: spatial evolution of damage and acoustic emission activity. J Struct Geol. https://doi.org/10.1016/j. jsg.2003.09.002

Baud P, Vinciguerra S, David C et al (2009) Compaction and failure in high porosity carbonates: mechanical data and microstructural observations. Pure Appl Geophys. https://doi.org/10.1007/ s00024-009-0493-2

Baud P, Schubnel A, Heap M, Rolland A (2017) Inelastic compaction in high-porosity limestone monitored using acoustic emissions. J Geophys Res Solid Earth. https://doi.org/10.1002/2017J B014627

Brantut N, Heap MJ, Meredith PG, Baud P (2013) Time-dependent cracking and brittle creep in crustal rocks: a review. J Struct Geol 52:17-43

Cotterell B, Rice JR (1980) Slightly curved or kinked cracks. Int J Fract 16:155-169. https://doi.org/10.1007/BF00012619

Dautriat J, Sarout J, David C et al (2016) Remote monitoring of the mechanical instability induced by fluid substitution and water weakening in the laboratory. Phys Earth Planet Inter. https://doi. org/10.1016/j.pepi.2016.06.011

David C, Bertauld D, Dautriat J et al (2015a) Detection of moving capillary front in porous rocks using X-ray and ultrasonic methods. Front Phys. https://doi.org/10.3389/fphy.2015.00053

David C, Dautriat J, Sarout J et al (2015b) Mechanical instability induced by water weakening in laboratory fluid injection tests. $\mathrm{J}$ Geophys Res Solid Earth. https://doi.org/10.1002/2015JB011894

Delage P, Cui YJ, Schroeder C (1996) Subsidence and capillary effects in chalks. In: ISRM International Symposium-EUROCK 1996

Delle Piane C, Sarout J (2016) Effects of water and supercritical CO2 on the mechanical and elastic properties of Berea sandstone. Int J Greenhouse Gas Control. https://doi.org/10.1016/j.ijggc .2016.06.001

Desrues J, Chambon R, Mokni M, Mazerolle F (1996) Void ratio evolution inside shear bands in triaxial sand specimens studied by computed tomography. Geotechnique. https://doi.org/10.1680/ geot.1996.46.3.529

Dupuis C, Vandycke S (1989) Tectonique et karstification profonde : un modèle de subsidence original pour le Bassin de Mons. Annales de la Société géologique de Belgique

Fabricius IL (2007) Chalk: composition, diagenesis and physical properties. Bull Geol Soc Denmark 55:97-128

Faÿ-Gomord O, Soete J, Katika K et al (2016) New insight into the microtexture of chalks from NMR analysis. Mar Pet Geol. https ://doi.org/10.1016/j.marpetgeo.2016.04.019

Faÿ-Gomord O, Soete J, Davy CA et al (2017) Tight chalk: Characterization of the 3D pore network by FIB-SEM, towards the understanding of fluid transport. J Petrol Sci Eng. https://doi. org/10.1016/j.petrol.2017.05.005 
Han B, Xie SY, Shao JF (2016) Experimental investigation on mechanical behaviour and permeability evolution of a porous limestone under compression. Rock Mech Rock Eng. https://doi. org/10.1007/s00603-016-1000-6

Heap MJ, Baud P, Meredith PG et al (2009) Time-dependent brittle creep in darley dale sandstone. J Geophys Res Solid Earth. https ://doi.org/10.1029/2008JB006212

Heggheim T, Madland MV, Risnes R, Austad T (2005) A chemical induced enhanced weakening of chalk by seawater. J Petrol Sci Eng. https://doi.org/10.1016/j.petrol.2004.12.001

Homand S, Shao JF (2000) Mechanical behaviour of a porous chalk and water/chalk interaction, part I: experimental study. Oil Gas Sci Technol. https://doi.org/10.2516/ogst:2000044

Jaeger J, Cook NG, Zimmerman R (2007) Fundamentals of Rock Mechanics(4E). John Wiley \& Sons, Hoboken

Kranz RL, Scholz CH (1977) Critical dilatant volume of rocks at the onset of Tertiary creep. J Geophys Res. https://doi.org/10.1029/ jb082i030p04893

Lai P, Krevor S (2014) Pore scale heterogeneity in the mineral distribution and surface area of Berea sandstone. In: Energy Procedia

Leonard M, Kennett BLN (1999) Multi-component autoregressive techniques for the analysis of seismograms. Phys Earth Planet Interiors 113(1-4):247-263

Madland MV, Hiorth A, Omdal E et al (2011) Chemical alterations induced by rock-fluid interactions when injecting brines in high porosity chalks. Transp Porous Media. https://doi.org/10.1007/ s11242-010-9708-3

Mavko G, Mukerji T, Dvorkin J (2009) The rock physics handbook. Cambridge University Press, Cambridge

Nicolas A, Fortin J, Regnet JB et al (2016) Brittle and semi-brittle behaviours of a carbonate rock: Influence of water and temperature. Geophys J Int. https://doi.org/10.1093/gji/ggw154

Risnes R, Haghighi H, Korsnes RI, Natvik O (2003) Chalk-fluid interactions with glycol and brines. Tectonophysics. https://doi. org/10.1016/S0040-1951(03)00187-2

Risnes R, Madland MV, Hole M, Kwabiah NK (2005) Water weakening of chalk-mechanical effects of water-glycol mixtures. J Petrol Sci Eng. https://doi.org/10.1016/j.petrol.2005.04.004

Robaszynski F, Dhondt AV, Jagt JWM (2002) Cretaceous lithostratigraphic units (Belgium). Geol Belgica. https://doi.org/10.20341 /gb.2014.049

Røyne A, Bisschop J, Dysthe DK (2011) Experimental investigation of surface energy and subcritical crack growth in calcite. J Geophys Res Solid Earth. https://doi.org/10.1029/2010JB008033

Røyne A, Dalby KN, Hassenkam T (2015) Repulsive hydration forces between calcite surfaces and their effect on the brittle strength of calcite-bearing rocks. Geophys Res Lett. https://doi. org/10.1002/2015GL064365

Sarout J, Esteban L, Piane CD et al (2014) Elastic anisotropy of Opalinus Clay under variable saturation and triaxial stress. Geophys J Int. https://doi.org/10.1093/gji/ggu231

Sarout J, Cazes E, Delle Piane C et al (2017) Stress-dependent permeability and wave dispersion in tight cracked rocks: experimental validation of simple effective medium models. J Geophys Res Solid Earth. https://doi.org/10.1002/2017JB014147

Schroeder C, Shao J (1996) Plastic deformation and capillary effects in chalks. In: Fifth North Sea chalk symposium SPE/ISRM programme committee, Reims, France

Stanchits S, Mayr S, Shapiro S, Dresen G (2011) Fracturing of porous rock induced by fluid injection. Tectonophysics. https://doi. org/10.1016/j.tecto.2010.09.022

Vajdova V, Baud P, Wong TF (2004) Compaction, dilatancy, and failure in porous carbonate rocks. J Geophys Res Solid Earth. https://doi. org/10.1029/2003JB002508

Vandycke S (2002) Palaeostress records in Cretaceous formations in NW Europe: extensional and strike-slip events in relationships with Cretaceous-Tertiary inversion tectonics. Tectonophysics. https://doi.org/10.1016/S0040-1951(02)00365-7

Vandycke S, Bergerat F, Dupuis C (1991) Meso-cenozoic faulting and inferred palaeostresses in the Mons Basin, Belgium. Tectonophysics. https://doi.org/10.1016/0040-1951(91)90103-Y

Vinciguerra S, Trovato C, Meredith PG et al (2006) Understanding the seismic velocity structure of Campi Flegrei caldera (Italy): From the laboratory to the field scale. Pure Appl Geophys 163:2205-2221

Voake T, Nermoen A, Ravnås C et al (2019) Influence of temperature cycling and pore fluid on tensile strength of chalk. J Rock Mech Geotech Eng. https://doi.org/10.1016/j.jrmge.2018.12.004

Wild KM, Amann F, Martin CD, Wassermann J, David C, Barla M (2015) Dilatancy of clay shales and its impact on pore pressure evolution and effective stress for different triaxial stress paths. In: 49th US Rock Mechanics/Geomechanics Symposium. American Rock Mechanics Association

Wong TF, Baud P (2012) The brittle-ductile transition in porous rock: a review. J Struct Geol 44:25-53

Wong T, David C, Zhu W (1997) The transition from brittle faulting to cataclastic flow in porous sandstones: mechanical deformation. J Geophys Res Solid Earth. https://doi.org/10.1029/96jb03281

Xie SY, Shao JF, Xu WY (2011) Influences of chemical degradation on mechanical behaviour of a limestone. Int J Rock Mech Min Sci. https://doi.org/10.1016/j.ijrmms.2011.04.015

Zhang J, Wong T-F, Davis DM (1990a) Micromechanics of pressureinduced grain crushing in porous rocks. J Geophys Res. https:// doi.org/10.1029/jb095ib01p00341

Zhang J, Wong TF, Yanagidani T, Davis DM (1990b) Pressure-induced microcracking and grain crushing in berea and boise sandstones: acoustic emission and quantitative microscopy measurements. Mech Mater. https://doi.org/10.1016/0167-6636(90)90026-C

Publisher's Note Springer Nature remains neutral with regard to jurisdictional claims in published maps and institutional affiliations. 